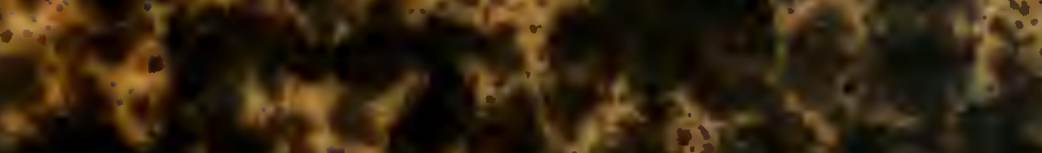

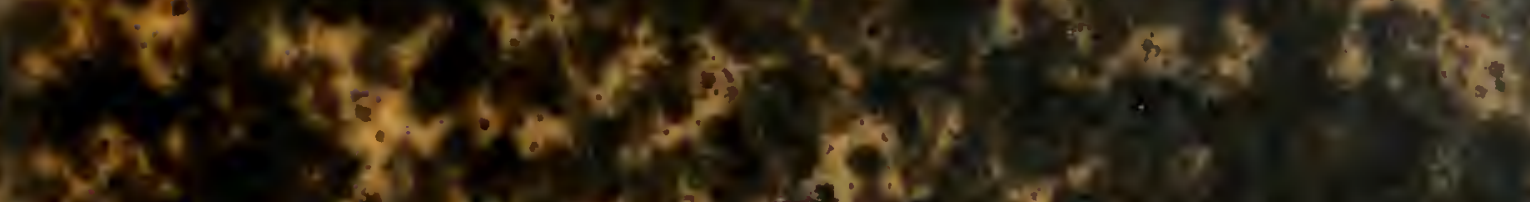

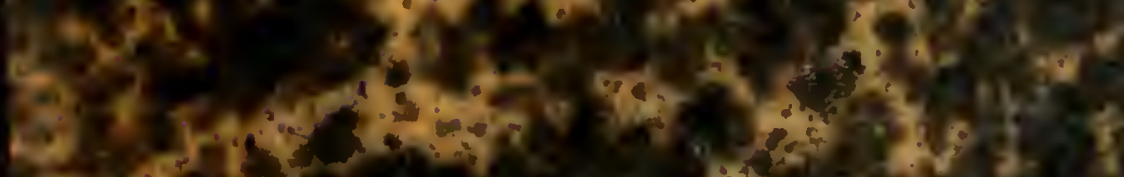

\title{
सts.
}

te

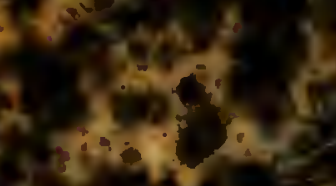
v

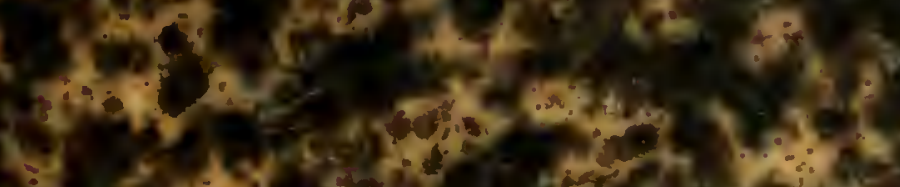

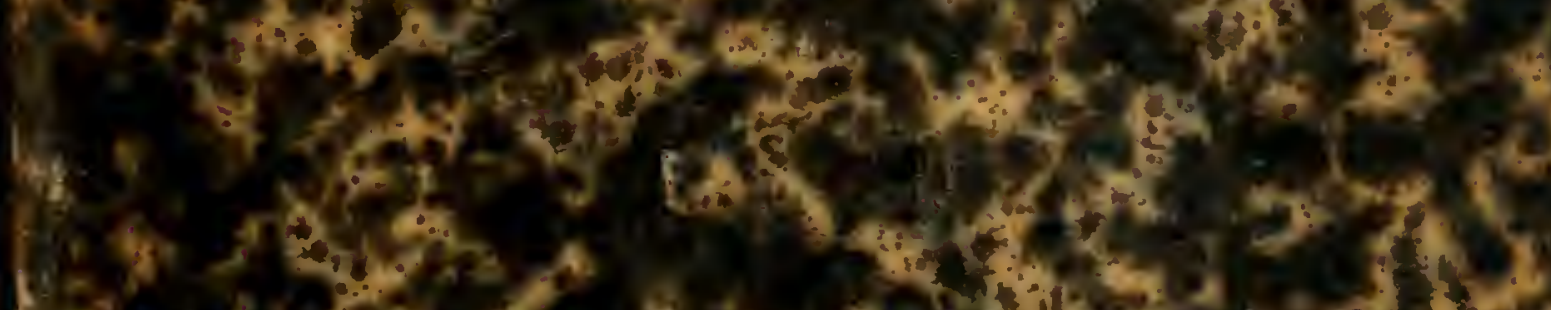

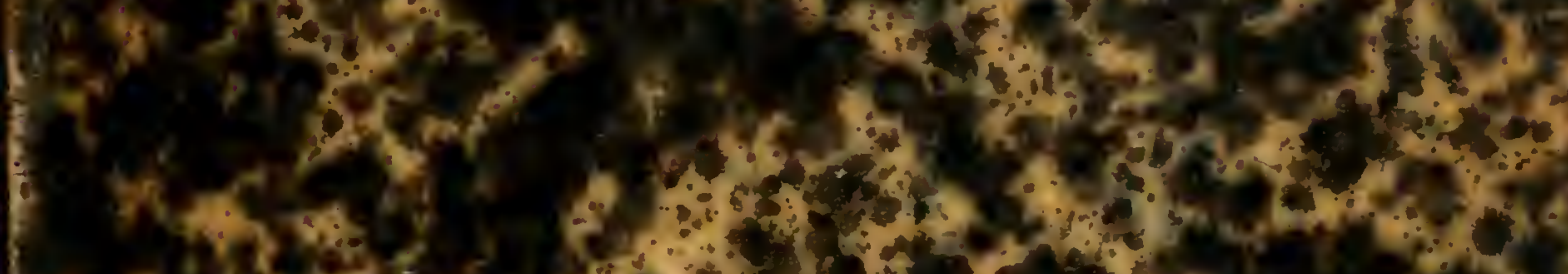

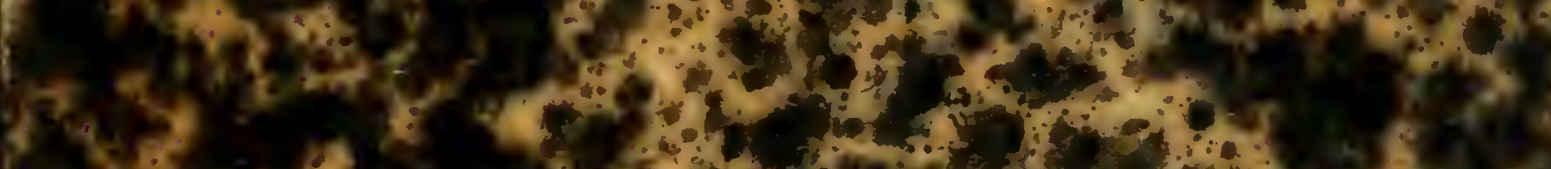

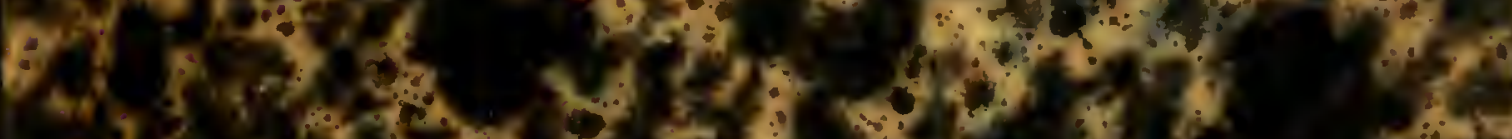

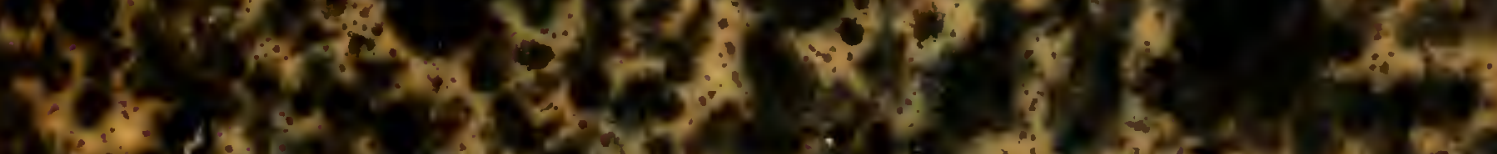

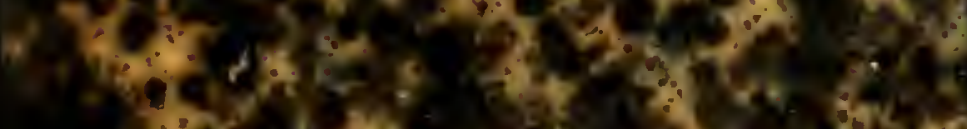

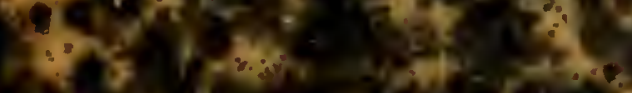

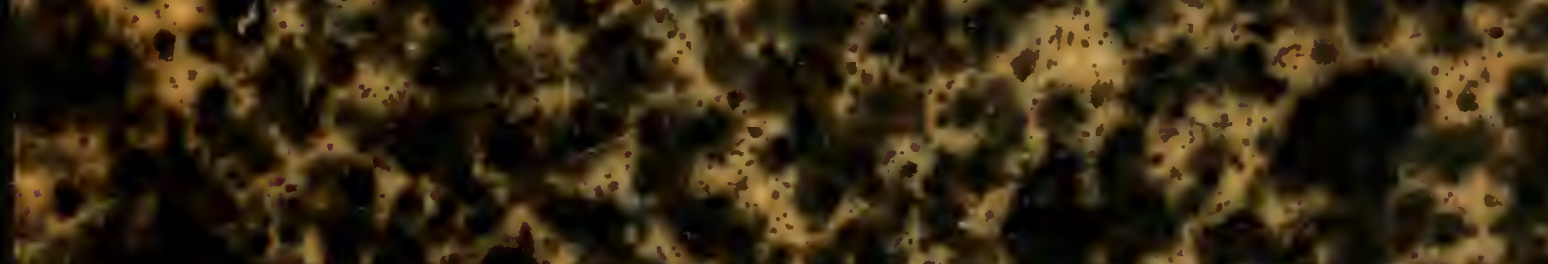

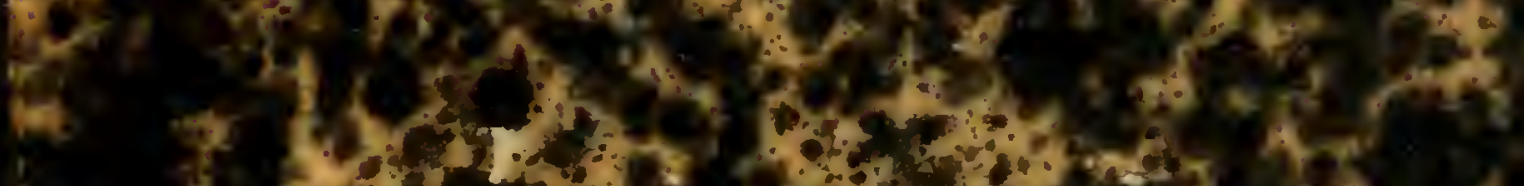
1.

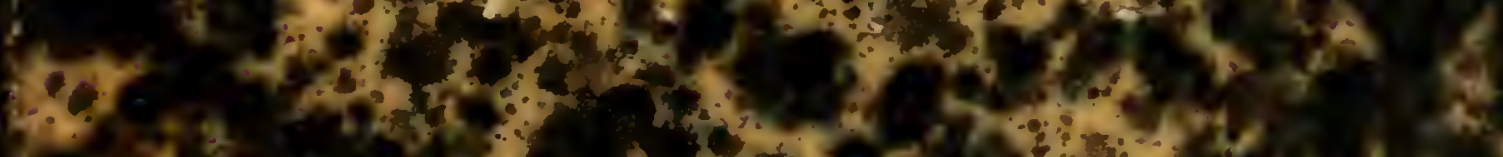
W.

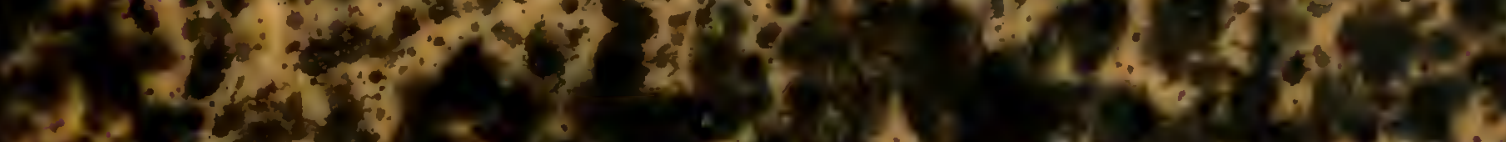

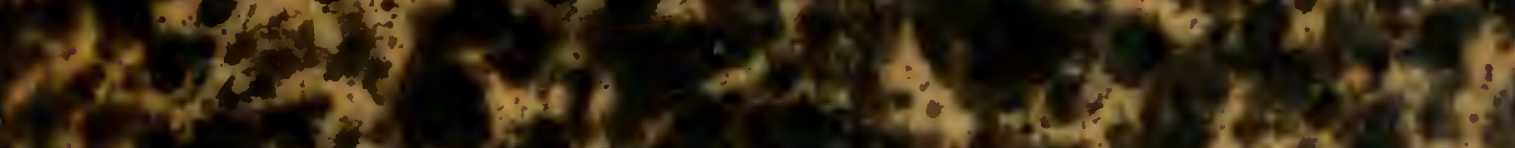

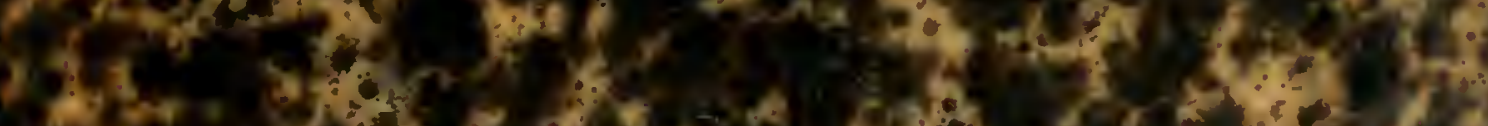

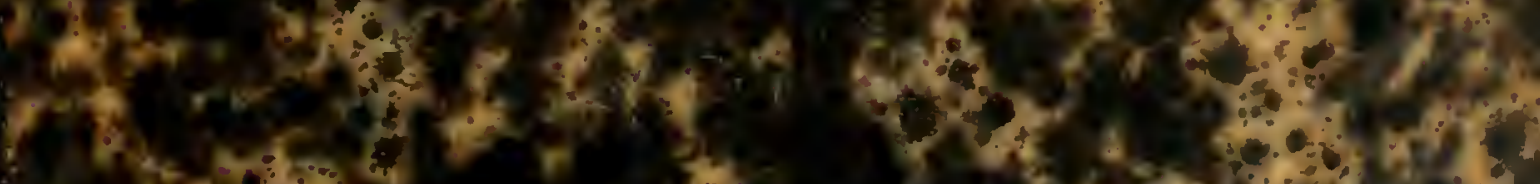

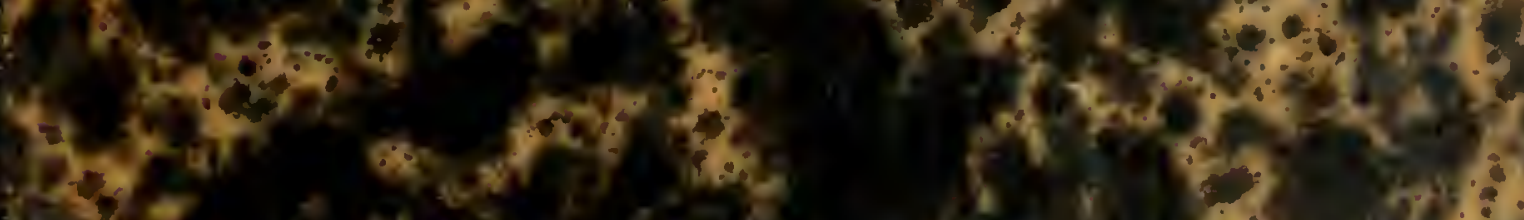

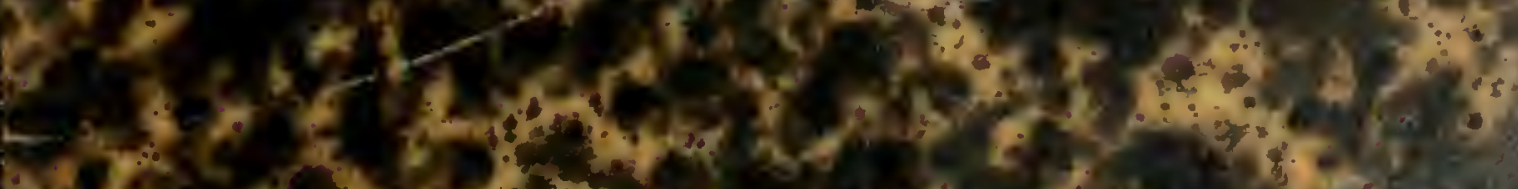

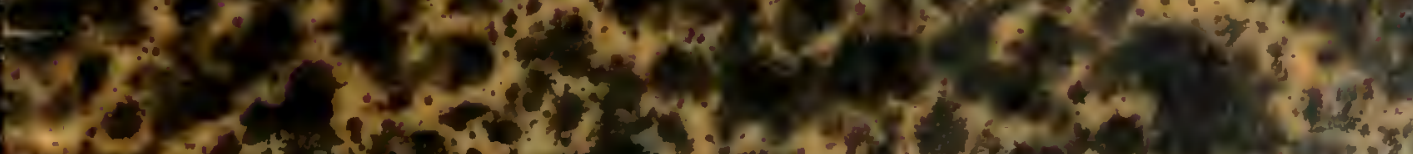

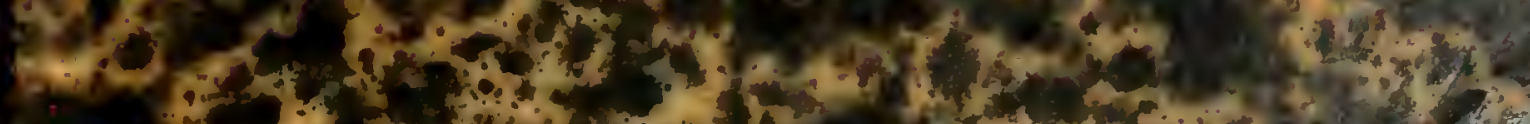






\section{LES SCIENCES}

\section{PENDANT LA TERREUR}

D'APRES LES

DOCUNENTS DU TEMPS ET LES PIÈCES DES ARCHIVES NATIONALES

$\operatorname{PAR}$

\section{G. POUGHET}

Avec avertissement, nolcs et corrections

ran

J. GUILLA UME

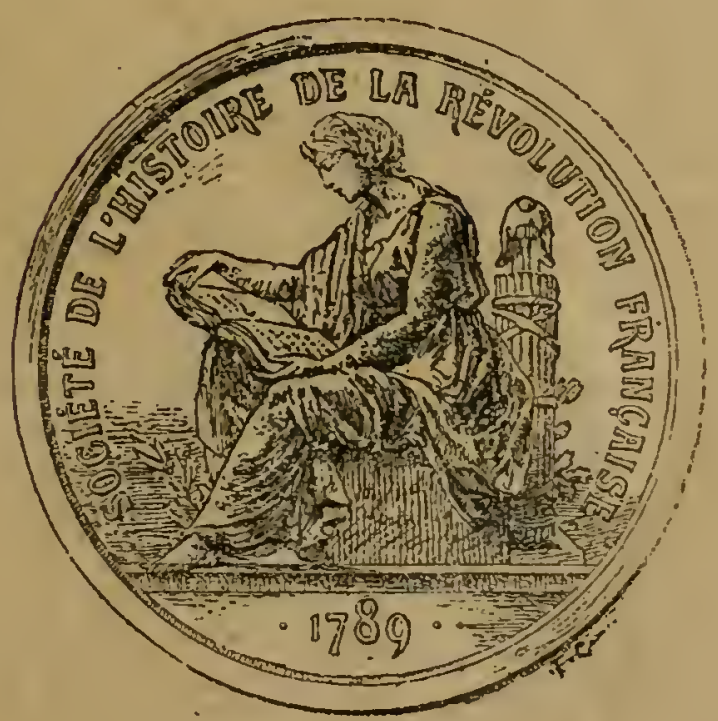

PARIS, AU SIEGE DE LA SOCIETÉ

3 , RUE DE FURSTEXBEHG, 3

1896 
SOCHETE

DF.

L'HISTOIRE DE LA REVULUTION FRANCAISE

Anciens mésidents de la Societe: MM. Hippolyte Carnot el Edouard Cilartor.

Ancion président d'homour: M. Cannot, président de la Républinjue.

BUAEAU :

Président: M. Jules Charirite, de l'Académie française.

Vice-présidenls: MII. Jules GulfFrer, archiviste paléographe, direcleur de la manufacture nationale des Gobelins; F. -A. A ULARD, prolęsseur d’histoire de la liévolution française à la Faculté des leltres de Paris; Errexse Chandray, archiriste paléographe. (M. Charavay remplil également les fonclions de Trésorier.)

Secrétaire général: M. Maurice Tounseux.

Secrélaire général adjoint: M. J. Gutlondme.

MEMBRES DU COMITÉ DIRECTEUR :

M.M. Lovis Anlable, conseiller à la Cour d'appel d'Aix-enProvence: - A. Bhetor, publicisle; - Edme Cuanpion, publiciste;-Ca.-L. Cinassin, publiciste: - A. Debinour, inspecteur général de l'Universilé; - H. Der'asse, publiciste;-A. Docarcue, premier président à la Cour d'appel de Caen;-Artovis Dubost, dépulé; - Adrien Duvand, publicisle; - Frarçors Flameng, artisle peintre; - Jules Flanlieruoxt, professeur à la Faculté des leltres de Lille; - Ennest Hamer, sénaleur; - A. Kizapfes, dirceleur des musécs nationaux; - G. Larrocinet, membre de l'Institul, professeur à la Faculté des lellres de Paris; - Enile Laubent, bibliothécaire en chel de la Chambre des députés; L. Liand, directeur de l'enseignement supérieur au ministère de l'hustruction publiquc; - II. Ilosis, professeur d'histuire au Collegge loollin el à l'llôtel de Ville: - Marcelisir Pelele, consul géneral de France à Genère; - Camille Pelletan, dépulé; Célestix Port, membre de linstilul, archiviste de Maine-elLoire; - Axtoxix Procst, ancien dépulé; - Alfred Ranbaud, ministre de l'Instruction publique; - I'. Roniocis', arocal an Cunseil d'Elat: - G. Slervors, walde général des hrchives natio-

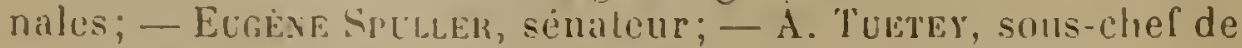
section aux Archires nationales.

Toules les communications relatives à la rédaction de la Revn: doireul èlre adressées à M. Aulard, place de l'Ecole, 1 . Paris. - La Direction n'est pas responsable des manuscrits non insérís. 


\section{LES SCIENCES}

PENDANT LA TERREUR 

SOCIÉTÉ DE L'HISTOIRE DE LA RÉVOLUTION FRANÇAISE

\section{LES SCIENCES}

\section{PENDANT LA TERREUR}

D APRÉS LES

DOCUYIENTS DU TEYPS ET LES PIÈCES DES ARCHIVES MATIOAALES

P.A R

\section{G. POUCHET}

Avec avertissement, notes et corrections

PAR

\section{J. GUILLA UME}
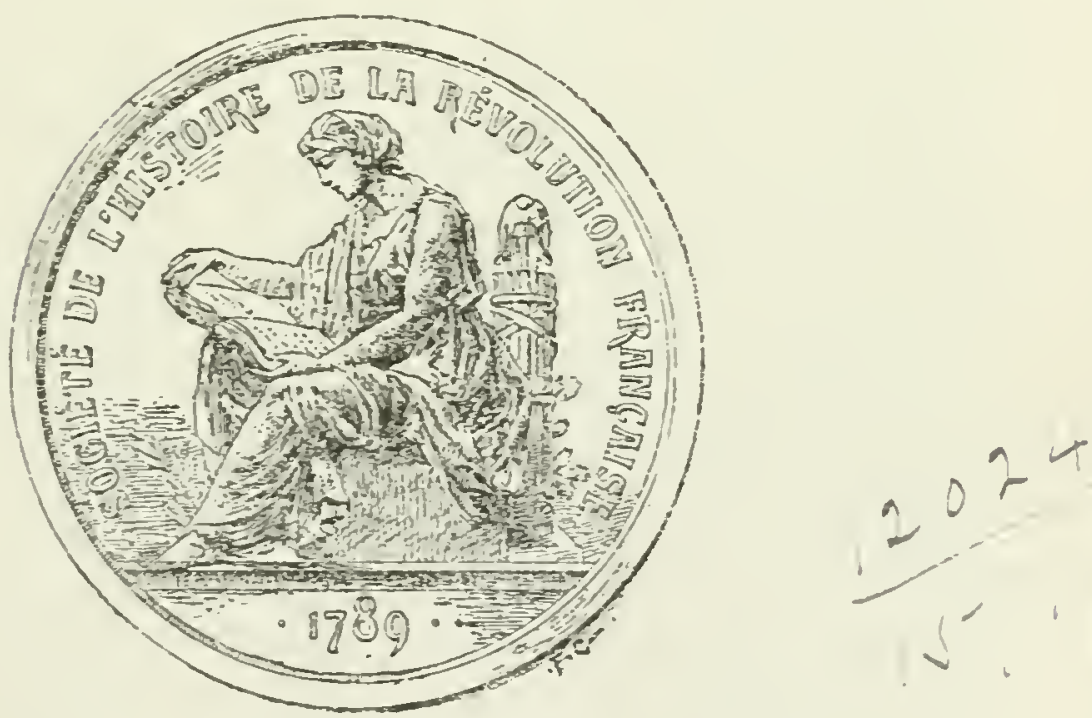

PARIS, AU SIEGE DE LA SOCIÉTÉ

3, RUE DE FURSTENBERG, 3 


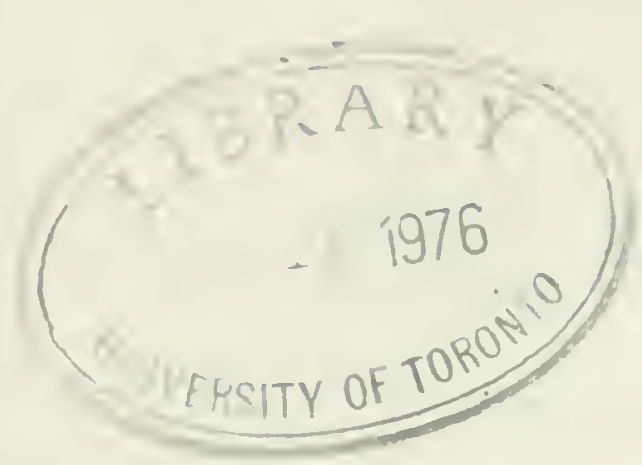

$$
\begin{aligned}
& \text { Ci } \\
& \text { FoP P }
\end{aligned}
$$




\section{AVERTISSEMENT.}

Le itravail de Georges Pouchet que nous réimprimons aujourd'hui (1) a paru dans la Philosophie posilive de Littré et Wyrouboff, numéros de novembre et décembre 1873. Il en a été fait un tirage à part à petit nombre, qui est devenu introuvable. C'était une tentalive très remarquable el très méritoire pour faire quelque lumière sur la période si mal connue qui va de septembre 1793 à thermidor an II. Les recherches de l'auteur confirmaient et complétaient les résultats exposés dès 1868 par Eugène Despois dans son livre célèbre, le Vandalisme révolutionnaire. Les faits recueillis par Georges Pouchel, empruntés presque tous à des documents d'archives, ont démontré victorieusement le bien-fondé de la thèse qu'il fut l'un des premiers à soutenir, et qui, à cette époque, pouvail encore passer pour un paradoxe aux yeux de la plupart : c'est que "l'an II marque bien réellement une date importante dans l'histoire des sciences françaises"; qu'à ce moment " non seulement elles sont représentées par une pléiade d'hommes

(1) Avec l'autorisation de la Socićté de Biulogie, que Georges Pouchet a instituée sa légataire universelle. 
illustres, non seulement elles voient grandir et naître une foule d'établissements d'enseignement, mais elles ont sauvé le pays "; et que le grand Comité de salut public, qui sut grouper autour de lui les savants et les artistes et les associer à sun œuvre, mérite qu'on lui rende "cette tardive justice, que plus qu'aucun gouvernement au monde il a honoré les sciences el compris leur rôle social ".

En réimprimant ces pages écrites par Georges Pouchet il y a vingt-trois ans, el qui ont conservé tout leur intérêt, nous avons scrupuleusement respecté le texte de l'auteur. Çà et là senlement, il nous est arrivé d'avoir à corriger une date ou un détail secondaire, à remplacer un nom propre par un autre, à amender ou à compléter une citation; nous l'avons fait sans nous croire tenu de prévenir le lecteur à chaque passage, estimant qu'il suffisait d'indiquer la chose une fois pour toutes dans cet avertissement (1). En deux ou trois endroils il nous a paru nécessaire, dans l'intérêt de la vérité historique, de relever des appréciations que nous jugeons erronées el qui provenaient d'une con-

(1) Nous allons montrer par quelques exemples la nature et la portée de ces légères retouches, que l'auteur aurait f'aites lui-même, s'il avait publié une nonvelle édition de son travail : Parlant du décret qui déclara le gouvernement révolutionnaire jusqu'ì la paix, Pouchet a placé entre parenthèses une date erronée, "12 octobre": nous rétablissons la date exacte: 10 octobre, 19 du premier mois; - à propos de l'Instruction sur la manière d'inventorier, publice par la Commission des arts, il dit que cette Instruction fut rédigée "dès prairial ": nous remplacons prairial par " nivôse ", late qui résulte de nos recherches récentes; - citant les auteurs de divers rapports faits au nom du Comité d'instruction publique, il nomme Chénier, Romme, Fourcroy, Thibaudeau, Boissy d'Anglas. Grégoire: nous supprimons les noms de Clénier et de Boissy d'Angras, qui neétaient pas membres du Comité à cette date; - il inilique, comme composant la Commission des poids et mesures, en septembre 1793, Cassini, Monge, Borda, Conlomb, IIaüy, Lavoisier : nous biflons le nom de Cassini, qui n'a jamais fait partic de la Commission, et mous ajoutons cerx de Lagrange, Laplace, Mécluain, Delambre, Brisson et Vandernonde; - à propos du procès des fermiers généraux et de Lavoisier, nous supprimous la mention de Cambon, pour restituer au rapporteur Dupin le rôle qui lui appartient. 
naissance incomplète de certains fails particuliers (1). Quant aux notes dont Georges Pouchet avait accompagné son texte, nous les avons reproduites, en les complélant quelquefois, et en rectitiant, là où il était besoin, soit les renvois, soit les cotes des pièces d'archives (les cotes de certains cartons des Archives nationales ayant été changées récemment). Nous avons aussi ajouté quelques autres notes contenant des éclaircissements nouveaux. Nos notes, ainsi que les additions aux notes de l'auteur, sont placées entre crochels et distinguées par des iniliales.

\section{J. Gulllaume.}

(1) Les points sur lesquels portent ces rectifications, placées en notes, sont les suivants : la composition et l'esprit du Comité d'instruction publique en l'an II; l'attitude de la Société des Jacobins à l'égard des doctrines philosophiques des encyclopédistes; la date et l'esprit du projet de décret sur les fêtes nationales rédigé par Mathieu et publié par ordre du Comité d'instruction publique: la part prise par le Comité d'instruction publique dans l'organisation de l'Iustitut national de musique. 



\title{
LES SGIENGES
}

PENDANT LA TERREUR

\author{
D APRES LES
}

DOCUMEXTS DU TEMPS ET LES PIECES DES ARCHIVES NATIONALES

Depuis que la terro a tremblé, on a élevé à la bảle, par impatience et par peur, une immense digue de lieux communs, de sophismes, de phrases banales: que personne n'a examinés et que l'on est sommé de respecter sous peine d'être suspect de vouloir ramener le déluge.

QUNET.

C'est un sujet mille fois repris que de rappeler tout ce qu'a fait la Révolution pour la grandeur intellectuelle de la France, les établissements créés, les déconvertes accomplies, les progrès réalisés pendant ces années longues comme des siècles. IIais, dans cette histoire si remplie, la Constituante, la Législative, la Convention sont autant de périodes bien définies. Dans la durée même de cette Convention souveraine, on peut distinguer des époques direrses pendant lesquelles le régime politique et en quelque sorte le gouvernement de la France soni sen:iblement modifiés. En ce sens, le 31 mai qui vit la chute des Girondins, le 9 thermidor furent de véritables rérolutions. Le supplice de Robespierre et de ses amis inaugure un régime nouveau en meltant fin à l'omnipotence du grand Comité de salut public, dont les pouroirs, renourelés pendant près d'un an, devaient se confondre dans le souvenir des hommes avec le régime de la Terreur. 
Pendant ces époques si différentes, quel a été le sort des sciences et des institutions destinées à les répandre et à les protéger? A-t-il été le mème, a-t-il changé? La plupart des historiens, embrassant d'un coup d'œil toute la Révolution, ne font point la différence, ils ne voient que l'ensemble des résultats et des progrès accomplis dans les sciences, sans marquer les phases de ce gigantesque enfantement.

Qu'advint-il en particulier durant ces dix mois qui s'étendent de septembre 1793 au 9 thermidor, période pendant laquelle l'échafaud fut presque en permanence? Est-ce que toute initiative ne fut pas suspendue? Et se fit-il comme une sorte de silence intellectuel, où l'on entendait seulement le bruit des coups que portait la hache rérolutionnaire?

Cette opinion sur le régime auquel arait mis fin le 9 thermidor se fit joul dès le lendemain de la chnte de Robespierre, dans le rapport de Courtois à la Convention sur les événements de cette journée fameuse. Le chimiste Fourcroy, qui vient d'être porté au Comité de salut public, ne jugre pas moins sévèrement ces hommies qu'il accuse ( 7 vendémiaire an III) de " conspiration contre les progrès de la raison humaine ", leur prêtant " le plan danéantir les sciences et les arts pour marcher à la domination à travers les débris des connaissances humaines $) !$ Enfin n'a-t-on pas vu, en 1838, un autre conventionnel, un ancien membre du Comité d'instruction publique, que les sciences se sont habituées à honorer, Lakanal, dénoncer à l'indignation des savants cette époque "où nul n'osait, dit-il, se déclarer le défenseur des sciences au sein de la Conrention 》?

Or, on a précisément fait à Lakanal une sorte de réputation comme sauveur des sciences pendant la tourmente révolutionnaire. Il a eu ses panégyristes illustres jusqu'au sein des Académies; et lui-même, par des écrits habilement composés, n’a pas le moins contribué à s'élerer un piédestal (1). A la vérité, le mème mérite s'est trouvé partagé, et les biographes nont pas malıqué de l'attribuer à Fourcroy, à Monge, à tous ceux qui n'avaient pas cessé d'occuper, pendant la Terreur, des postes scientifiques importants. Ce titre de sauveur est au reste un de ceux qu'on se donne le plus rolontiers dans notre pays. N'avons-nous pas vu nous-mẻmes, après des journées de sang et de violence, une foule de gens se faire honneur d'avoir sauvé

(1) Exposé sommaire des travaux de Joseph Lakanal, Paris, 1838, in-8. 
des monuments qui n'eurent que l'arantage d'être oubliés par । un pouvoir insurrectionnel qui ne comptait pas avec les moyens d'exécution?

Il en coute certainement, quand on parle de Lakanal, de faire certaines réserves; mais il a rendu d'assez importants services pour que son rôle et son influence n'aient aucun besoin d'être encore exagérés, surtout par lui-mème. Tout au plus pourrait-on lui reprocher de n'aroir pas craint de livrer au public les lettres d'hommes de science le remerciant de légers services pécuniaires que leur avait rendus sa bourse (1). Il est certain que Lakanal déploya une grande activité pendant la première année que siégea la Convention, puis après la Terreur. Mais, à l'époque qui va nous occuper, Lakanal n'est point à Paris (2). Aussi, dans son mémoire laudatif sur lui-même, ne dit-il pas un mot, un seul mot, de ces mois terribles qu'il passa loin de l'assemblée, à rendre les services d'ailleurs les plus dévoués à ce gouvernement révolutionnaire de la France, pour lequel il devait dans la suite se montrer si sévère. Il passe sans transition de 1793 à l'automne de 1794, comme si un monde d'événements ne séparait pas ces deux dates entre lesquelles il scmble que rien n'ait été lait, lui absent, dans les sciences. Avant le début de la Terreur la collection du Louvre est créée, le Muséum réorganisé; le télégraphe, l'unité de poids et de mesures sont décrétés. L'an III et l'an IV verront la création de l'Ecole normale, l'organisation de l'Institut, l'Ecole des langues orientales, les cours des Ecoles centrales. Mais l'an II ne fut pas non plus sans travaux et sans gloire scientifiques aux jours les plus troublés de la Révolution.

Une remarque est ici nécessaire.

L'histoire des sciences, quoique toujours intimement unie à l'histoire politique, voit les hommes et les choses d'un autre œil. Pour elle Alcxandre n'est plus le fou furieux qui tue Clitus

(1) Lakanal s'est bien gardé de publier, dans les extraits de sa corresporldance, certain billet que l'on pourra retrouver à l'observatoire, où le protecteur" des savants traite Cassini du ton qu'eût pu prendre Herlin parlant à un émigrẻ. - [Le billet de Lakanal a été imprimé en 1894 dans le tome II des Procés-verbaux du Comité d'instruction publique de la Convention, p. 477; ce volume contient le texte complet de toutes les piéces relatives au conflit entre Cassini et les quatre "professeurs " de lObservatoire. - J. G.]

(2) [Lakaual fut envoyé en mission à Bergerac par décret du 17 du premier mois de l'an deuxième (8 octobre 1793); il ne revint à Paris quaprés le 9 thermidor, sauf deux courtes apparitions en nivóse et en germinal. - J. G.] 
et se fait dieu: c'est le conquérant qui donne aux connaissances géograpliques de la Grèce un champ nouveau, c'est l'élève d'Aristote envoyant à son maitie les animaux de l'Inde. Louis XIV n'est plus le monarque des dragonnades quand il fonde l'Académie des sciences, et Catherine II, elle-mème, devient intéressante quand, enfermée dans son pavillon d'étude, " elle cufourche - comme elle dit - son dada philologique et travaille it ses dictionnaires polyglottes ). Il se peut faire que certains hommes de la Rérolution se montrent à nous, de ce cỏlé, sous un jour un peu moins défavorable: Fouché fonde a Nevers un établissement d'instruction; cela seul nous importe, et non les fusillades qu'allait organiser à Lyon dans le mẻme temps le futur duc d'Otrante. Nous ne jugerons personne, nous bornant ì curegistrer des faits. Il faut une autre autorité que la nôtre et des reilles plus longues pour oser regarder en face les grandes figures de ce temps enveloppées dans leur suaire sanglant. Mais, avant de descendre les gémonies de l'an II, nous devions affirmer une fois de plus le ferme dessein de n'avoir dans ces pages d'autres préoccupations que la marche de l'esprit scientilique en France, pendant celte époque marquée par tant de deuils, mème pour la science.

La période de l'histoire de la Révolution daus laquelle nous nous renfermons a des limites précises. C'est le moment où la crise rérolutiomnaire attcint son paroxysme; c'est le triomphe de la Montagne, aussitôt compromis par l'influence dominante de l'esprit jacobin, du commencement de septembre 1793 au 9 thernidor an 11 (27 juillet 1794). Au 5 septembre, la Terreur - qu'arait demandée Danton dès le mois d'août - est par la Convention "mise à l'ordre du jour"; la loi des suspects est promulguée, l'armée rérolutionnaire instituée, le tribunal criminel extraordinaire, qui bientòt ( 8 brumairc) prendra le mème nom, réorganisé; le gouvcrnement est déclaré rérolutionnaire jusqu'i la paix (19 du premier mois, 10 octobre). A l'ennemi en armes sur toutes nos frontieres, à la moitié de la France soulevée, la Convention oppose la toute-puissance du Comité de salut public renouvelé aux mains des mêmes hommes jusqu'au 9 thermidor qui brisera leur pouvoir et commencera une ère nourclle. Au dehors l'ennemi repoussé, la Belgique occupée, la Hollande menacée; au dedans, Lyon rendu, Toulon 
repris, les Tendéens rejetés au delà de la Loire, a Paris le jugement des Girondins et de la reine, puis coup sur coup la chute des hébertistes et celle de Danton, puis la loi de prairial et la guillotine presqu'en permanence, tels sont les événements qui vont marquer cette année formidable, où la Rérolution menacée semble à jamais triomphante. On concerrait à la rigueur qu'une si grande dépense de forces ait pu un instant paralyser ce noble élan vers les sciences qui arail marqué les premières années de la Révolution et qui devait encore jeter un certain éclat sur les derniers jours de la Convention; et, s'iln'en a point été ainsi, qui donc furent les ourriers, qui fut l'âme des travaux accomplis au milieu de cette fournaise où rien ne subsistait du passé, oủ nul n'était sủr du lendemain?

Un des premiers soins arait été de sanver tous les objets de science et d'art, qui tombaient chaque jour par milliers aux mains de la nation. C'est l'origine de nos collections publiques, imitées depuis par les autres peuples. Il n'y en arait point à Paris, ni ailleurs, arant la Révolution. Les musées, les collections, les cabinets, les jardins botaniques, les bibliothèques ne manquaient point, mais tout cela appartenait au roi, aux sociétés, aux particuliers, aux couvents. Le public y était admis, mais seulement à titre gracieux, et le Guide des élrangers à Paris de 1777 en donne, pour la capitale, la liste complète. Ici c'était un cabinet de médailles, ou d'instruments de physique; ailleurs, des collections danatomie formées d'objets naturels ou de pièces en cire; celle de Chantilly était célèbre; dans d'autres on royait enlassées pêle-mêle des curiosilés de toute espèce, meubles précieux, oiseaux rares, marbres antiques, uslensiles de sauvages, émaux, pétrifications. On retrouve aujourd'hui de ces cabinets dans certains courents d'Italie, aux bénćdictins de Catane, par excmple, très sembiables à ce qu'ils deraient ètre à Paris au siècle dernier, dans les riches habitations de la noblesse et dans les maisons religieuses.

Depuis longtemps, il avait été décrété que les biens des communautés et des émigrés feraient relour à la nation. Pour receroir toutes ces richesses, la République avait déjà le Muséum des arts, qui deviendra le Musée du Louvre, et le Jardin des plantes réorganisé sous le nom de Muséum d'histoire naturelle. Mais ces établissements n'étaient point prèts; puis il fallait avant tout réunir les objets, en faire l'iuventaire, choisir ceux qui étaient dignes d'être exposés, enfin mettre à l'abri 
une foule de clıoses rares ou précieuses, contre le zèle iconoclaste des foules. Les célèbres rapports de l'abbé Grégoire sur le vandalisme sont postérieurs atu 9 thermidor; mais dès brumaire (1) la Convention arait fail défensc expresse de mutiler non seulement les monuments publics, mais les livres et les objets de toute sorte des collections, sous prétexte d'en faire disparaitre les signes de royauté ou de féodalité. Le Comité d'instruction publique, chargé de veiller a tout cela, ne pouvait évidemment pas descendre aux détails : dès l'origine il s'était adjoint des commissions, sur lesquelles il s'était en partie déchargé. Si l'unc d'elles, celle des monuments, fonctionna assez mal et mérita de voir la Convention suspendre ses travaux (?्), il en fut autrement de la Commission temporaire des arts, que l'on troure en pleine activité pendant tont le courant de l'an 11 . Elle fut réorganisée par un décret de l'asscmbléc du 18 pluviôse, qui en nomma définitivement les membres (3). Parmi les plus actifs pendant la période qui nous occupe, on peut citer l'anatomiste Vicq d'Azyr, premier médccin de la reine, Ameilhon et l'abbé Mongez, antiquaires, les botanistes Richard et Thouin, toujours en course pour sauver les arbres rares, os plantations d'ananas, les caisses d'orangers des demeures princières autour de Paris; le joaillier Nitot, le plıysicien Charles, Dufourny, qui partage son activité entre la Commission et le département de Paris, enfin le bénédictin dom Poirier. D'autres membres illustres, comme Monge, ne parurent que rarement aux séances, occupés qu’ils étaient ailleurs à de plus

(1) Décret rendu sur le rapport de Romme, le 3 du second mois de l'an 11.

(2) [Instituée en norembre 1790 par les Comités ecclésiastique et d'aliénation de l'Assemblée coustituante, réorganiscie le 18 octobre 1792 par la Convention, la Commission des monuments fut supprimée le 28 frimaire an 11 , sur le rapport de Mlathieu. - J. G.]

(3) [La Commission temporaire des arts a son origine dans le decret du 12 août 1793, ordonnant l'inventaire des objets appartenant aux Académies, et dans ceux des $1 ; j$ et 18 aoùt, chargeant quatre représentants, David, Ronme, Ilaussmann et Dyzez, de faire exéculer le décret du 12, et de faire en outre inventorier tous les objets utiles à l'instruction publique, appartenant i la mation. A la demande des qualre representants et des délégués du Comité d'instruction publique, le ministre de l'intérieur Paré nomma dans les delniers jours d'aoùt trente-six commissaires chargés de procéder anx inventaires prescrits. Ces commissaires, divisés en douze sections, formèrent la Commission des arts. La Convention en confirma l'existence par le décret du 28 frimaire, et la substitua a la Commission des monuments. Un dicret lu 18 plurióse la réorgauisa et la composa de quarante-trois membres, dont ringt-deux araient figuré au nombre des commissaires nommés par le ministre. - J. G.] 
pressants besoins pour la défense du territoire. Le décret du 18 pluriôse attribua une indemnité aux membres de la Commission temporaire qui n'avaient pas de traitement pour d'autres fonetions, le cumul étant interdit.

On a comparé tout à fait à tort la Commission des arts à une compagnie scientifique ou littéraire. On a même dit qu'elle pourait être considérée comme remplissant sans trop de désarantage l'intérim entre les Académies supprimées dès le mois d'août à la demande de Grégoire, et l'Institut qui ne sera organisé que plus tard. C'est se méprendre complètement sur le rôle de la Commission des arts, qui fut, arant tout, exécutive, sorte de pouroir savant dans l'Etat, dont on ne retroure point l'analogue. Elle fait mettre les scellés par deux commissaires spéciaux à ses ordres; elle a la direction et la responsabilité des dépôts; et les dépenses de transports finissent par s'élever tellement qu'elle obtient d'employer l'administration des charrois de l'Etat : c'était une économie de 15,000 livres par mois. Elle déploie une activité prodigieuse, comme au reste le gouvernement, les administrations, les armées, la science mème à cette époque de fièrre. Ses registres attestent à la fois le nombre et la variété des affaires qui lui passent par les mains. Elle siège deux fois par déeade; un seul jour la séance n'eut pas lieu, c’était le 10 thermidor (1), puis ses traraux reprennent leur cours, que les grands érénements qui riennent de s'accomplir ont à peine troublé. 0 n avait pu roir seulement percer à travers ses délibérations le poids chaque jour plus grand dans l'Etat de ce Comité de salut public qu'on renait de décapiter. La Commission des arts avait même fini par insérer, avec une sorte d'importance, à ses procès-rerbaux les arrêtés qu'elle en reçoit. Etait-ce crainte? Sans parler des opinions personnelles des hommes de science à cette époque, c’est assurément en méconnaître le caractère que de leur supposer un tel sentiment. La peur ne fut pas plus de ce temps-là que les larmes, et nous ne voyons pas qu'un seul homme de science ait cherché à se dérober, par une fuite facile, au gouvernement légal du pays. Lakanal roudrait laisser croire qu'il a travaillé à les retenir.

(1) [La Commission des arts ne tint pas séance d'une façon aussi régulière que l'a cru Pouchet. Ses dix premiẻres séances eurent lieu sous le régime de l'ancien calendrier, du 1 er septembre au 3 octobre 1793. Elle s'assembla ensuite le 20 du premier mois, les 50 , 10, 20 et 25 brumaire. A partir de frimaire, elle se réuuit six fois par mois; néanmoins la sẻance n'eut pas lieu le 20 prairial, jour de la fête de l'Être-Suprême, ni le 10 thermidor. - J. G.] 
Peine bien inntile, pensons-nous, s'il se l'était donnée en effet, mais oll a vu qu'il n'élait pas mène a l'aris. Chose remarquable, on ne trouve pas un seul homme de science parmi les émigrés, non plus qu’i Lyon, à 'Toulon, en Vendée. Tous avaient embrassé la cause de la Rérolution. Chaptal écrit des hrochures de parti; si Condoreet se tue comme girondin perrdant la Terreur, Monge s'enfuira après thermidor comme jacobin. C'est un point quon ne doit jamais perdre de vue. On oublie trop que ces hommes ont vécu et ont dù virre, en ellet. de la vie de leur temps.

On annonce a la Commission des arts, d'un district de province, la découverte d'un certain nombre de portraits, mais qui représentent des personnages frappés par le glaive de la loi : elle répond aux administrateur's de les brüler et d'assister au brủlement. Un autre jour, le 14 germinal, le secrétaire grefficr de la commune de Paris adresse à la Commission deux médạillons de bronze représentant Lafiryette el Bailly (1); comme ils nont pas la valeur artistique que leur supposaicnt les membres de la commune, fort ignorants en ces matières, la Gummission ordonne qu'ils seront mutilés aussitôt et les fragments lirrés à la forte (2). Trois mois après, les esprits peu à peu se sont encore exaltés. En vain un membre de la Commission fait observer qu'il se pourrait trouver quelque portrait de l'ex-famille royale précieux au point de rue de l'art, la Commission arrête (sur la proposition de Picault et de Taron), que "Lous les lableaux et portraits représentant des individus de la race Capet seront inventoriés et réunis dans un mème dépòt, et que l'on procédera à leur destruction totale el complète, afin que la superstition royaliste ne puisse en recueillir aucun. Malgré les observa-

(1) Exllait du procis-rerhal du Conseil général de la commune du 9 germinal: "toe citoreu Laurent dépose sur le burean deux médailles, l'une représentant Bailly et l'autre Lafayelte. Le Conseil gínéral, ru la perfection de l"ourrage, considérant que leffigie des trailres peut itre conservée pour ètre vouce a lexécration des races fulures, urrite que le secrétaire yreffier est autorisé à envoyer ces leux médailles ả la Commission des arts pour étre soumise's $i$ son jugement el conservées, si elle le juge runverable. (Archires nationales, Fit, carton 104\$).

(2) Registre de la Commission des arts, 13 germinal. - On lit ä la date du 30 gelminal : "Jiexamen des dillerents ubjets d"imposture religieuse. inoucés par le citoyen lelievre, et entre autres du lait de la sainte vierge. est renroyé a la scction de chimic n. - [Le registre de la Commission des arts, dont il est question lans crtte note et les suirantes, se troure aux Archives nationa!es sous la cole $\mathrm{F}^{17^{*}} \mathrm{i}$ : il e:t intitulé Noles et arrétés de la Commision des arts, et contient les procés-verbaux des séances de la Cominission du fer septewbre 1793 au 10 vendémiaire an 111 inclusivement. - J. G.] 
tions d'un membre, la Commission, ferme dans ses principes, maintient son arrêté. »

Les attributions de la Commission des arts étaient aussi complexes que mal définies. Elle concentra dans ses dépóts tous les objets ayant une valeur artistiqus, littéraire ou scientifique quelconque, livres, statues, tableaux, instruments, modèles, armes précieuses, médailles, tout enfin : la tête de Cartouche (1) aussi bien que les tables en mosaïque du boudoir de MarieAntoinette; la momie de Turenne (2), d̀ côté d'une girafe empaillée (3) du cabinet Le Vaillant, " objet que l'Europe n'a jamais vu aussi beau, et qu'il était réservé au zèle d'un royageur infatigable d'offrir pour la première fois aux regards étonnés des Français ». La Commission dresse l'inventaire des richesses extraites des églises, des demeures royales, des habitations d'émigrés ou de condamnés. Elle est à la piste de tout ce qui tombe légalement au pouvoir de la nation, elle examine tout; chez Hérault de Séchelles, elle retrouve les manuscrits de l'Emile et de la Nouvelle Hiloüse avec le portrait de $\mathbf{M}^{\text {me }}$ de Warens (4). Mais un amas de coquilles sur le coin d'un plancher ne l'occupe pas moins, et elle dẻlègue un de ses membres pour lui rendre compte de la raleur que cela peut bien avoir (5). Un autre jour elle est arisée que Iontmorency le fils, en partant pour l'émigration, a dû cacher plusieurs caisses remplies d'objets d'histoire naturelle chez un de ses valets de chambre nummé Lebas, qu'on suppose habiler la rue des Piques. Mais ce Lebas est introurable; on s'est adressé au comité civil et au comité révolutionnaire de la section. Lebas a dù se sauver ou changer de nom, et voilà toutes ces richesses perdues. "Ce n'est pas de l'individu dont nous arons besuin, dit le rapporteur de l'affaire, mais bien des objets qui peuvent servir à l'instruction nationale. » Il y a cependant un dernier moyen de les retrouver. Le suisse du ci-devant hotel Montmorency, un nommé Poquelin, est présentement incarcéré aux Madelonnettes; la Commission décide qu'un de ses membres se rendra

(1) Registre de la Commission des arts, 19 septembre 1793. Cette tête avait été injectée par Hérissant.

(2) Registre, 22 septembre 1793 et 10 frimaire. Cotle momie, enlevée de Saint-Denis, fut déposée au Muséum dans la galerie d'anatomie.

(3) 23 messidor. Archives nitionales, $F^{17}$, carton 1081.

(4) Kapport de Richard à la Comwission des arts, 25 germinal an 11 . (Fi7, carton 1224).

(5) Rapport de Lamarck á la Commission des arts sur un amas de coquilles à Pussy. ( $F^{17}$ carton 1224). 
vers le Comité de sûreté générale pour avoir l'autorisation de communiquer avec cet individu et tâcher d'apprendre de lui où sont les précieuses caisses (1).

En dépil de toute la vigilance de la Commission des arts, il y eut, nous n'arons pas besoin de le dire, beaucoup de rapines commises.

Les objets de valeur laissés par les émigrés ou par les condamnés étaicnt souvent soustraits; on essaya de faire sortir de France unc partic du mobilier de la Du Barry à Louveciennes; on trouvait sur la grande route, aux portes de Paris, une cassette pleinc de médailles et de camées, perdue par quelque fuyard on quelque volcur (2). Les geỏliers, de leur côté, étaient assez peu scrupuleux. La Commission sollicite du Comité de salut public, à plusieurs reprises, des mesures pour arrêter les abus. Elle s'adresse aussi pour cela à l'accusateur public près le Tribunal révolutionnaire. Il s'agit ce jour-là de retrouver une montre à longitudes, ouvrage d'un célèbre constructeur anglais et que Bochart de Saron, ancien président au parlement de Paris, avait portée sur lui jusqu'au dernier jour. En quittant la prison pour l'échafaud, il avait dû la remettre à la femme du portier, qui l'avait gardée. Fouquier-Tinville fit-il rendre la montre? Tont ce que nous savons, c'est qu'elle rentra aux mains de la Commission (3). Nous royons encore celle-ci réclamer, auprès du conseil du Temple, une montre à secondes en platine à boîte en or émaillée que «le ci-devant roi " a dú laisser en allant à la mort (4).

Tous ces objets viennent s'entasser méthodiquement dans divers dépôts; ils sont inventoriés, catalogués avec le plus

(1) Rapport de Leliçrre a la Commission des arts ( $F^{17}$, carton 122f). L’affaire était en effet au Comité de sûreté géuérale le 23 frinairc $\left(F^{17}\right.$, carton 1225, et registre de la Commission des arts, 25 et 30 frimaire). Les caisses furent sans doute découvertes, car nous royons Richard faire à la Commission des arts un rapport sur le transport du cabinet d'histoire naturelle de l'émigré Montıiorency. (Regristre, 30 pluviôse.)

(2) "La commune de Paris aux représentants composant le Comité de salut public, 2.j messidor: La citoyenne Dugy, roiturière, a trouvé dans la forêt de Bondy et déposé une boite contenant une collection, précieuse pour les arts et pour l'histoire, de médailles frappées sous le tyran Louis $\mathrm{IIV}$, et représentant l's tráits de valeur de nos äeux que ce tyran appelait ses victoires. Ces médailles, quoique souillées de l'effigie d'un roi, nous paraissent mériter place dans les Archives nationales. Elles ne sont pas réclamées et ne le seront probablement jamais." (Fi7, carton 10.8.)

(3) Registre de la Commission des arts, 23 floréal.

(4) Registre, วँ messidor. 
grand soin. Au moment mêrne où Hoche recule à Kaiserlautern, le Comité de salut public n'a point la carte des Pays-Bas autrichiens, de Ferraris; il la demande le 10 frimaire, et le 15 la Commission des arts en a trouvé deux exemplaires dont un incomplet (1).

Le Comité d'instruction veut avoir sous la main une bibliothèque pour aider à ses travaux et à ceux des autres Comités (2). Le Comité de salut public lui-mème (3) en veut une dans son local (ces hommes avaient donc le temps de consulter des livres?). Les dépôts fournilont tout cela. La Commission des armes, elle aussi, a besoin d'ouvrages spéciaux, d'instruments, de modèles de canons provenant de l'arsenal; et comme tout presse ici, il est convenu qu'on les délivrera sur un simple récépissé de Guyton, le chimiste (4). La bibliothèque du Jardin des plantes, déjà instituée (̋ั), va s'enrichir de ces dépôts; on est même obligé de modérer le zèle des professeurs, qui ne demandent qu'à prendre (6). Puis ce sont les fourneaux, les réci-

(1) Registre le la Commission des arts, 15 frimaire.

(2) Du 23 pluviôse an II : "Vu l'arrêté du Comité d'instruction publique du 1 er de ce mois, qui charge les citoyens Guyton et Fourcroy de communiquer au Comité de salıt pıblic le projet d'établir près dı Comité d’instruction publique une bibliothèque... qui mettrait à la portée des Comités des livres dont ils ont besoiu journeltement, et particulièrement ceux qui traitent des arts qu'il importe de répandre et de perfectionner comme moyen de force et de prospẻrité de la République; le Comité de salut public, considérant que la collection qu'il a désiré aroir sous sa main, et dans le lieu même de ses séances, ne pourrait remplir entièrement l'objet proposé; qu'il a chaque jour besoin de grands recueils de physique, mẻcanique, etc., et, dans le moment actuel, des Transactions de la Société de Londres;... arrête qu'il sera incessamment formé dans le local du Comité d'instruction publique une collection des meilleurs ourrages sur les objets relatifs aux travaux des diffẻrents Comités de la Convention nationale. Signé au regist, e : Robespierre, Carnot, Barère, Couthon, C.A. Prieur, Jeanbon Saint-André, R. Lindet, Billaud-Varenne. Pour extrait : Carnot, C.-A. Prieur, Barère, Billaud-Varenne. (Archires nationales, $F^{17}$, carton 1306.$)$

(3) Registre de la Commission des arts : "Sur la demande du Comité de salut public, la commission charge les membres de la section des dépôts littéraires de faire dans les bibliothèques des émigrés ou condamnés uu choix des livres qui derront composer la bibliothèque que ce Comité se propose d'établir pour son usage. " (2ङ floréal). - "Les mêmes commissaires sont invités à concourir de tous leurs soins all complément de la bibliothèque du Comité d'instruction publique. "(30 floréal).

(4) Registre de la Commission des arts, 30 nivôse, 5 ventôse, 25 prairial.

(5) La bibliothèque du Muséum était en pleine formation dès le mois d'août 1793. Voir différentes pièces aux Archires nationales, $F^{17}$, carton 1227.

(6) Registre de la Commission des arts, כ̋ ventôse. 
pients, les ustensiles de toute sorte destinés aux laboratoires (1) de la nouvelle école pour la fabrication dı salpêtre (15 ventôse). L'Observatoire national demande les instruments d'astronomie laissés par Bochart de Saron, qui lui sont attribués sur le rapport du plysicien Charles (2).

Les particuliers s'adressent aussi à la Commission des arts; l'un demande une lunette de passages dont il a besoin pour faire des observations; pour un autre, c'est un microscope solaire. Tout cela est immédiatement trouvé et délivré sur récépissé en forme, car la Commission a mis un ordre admirable dans ce monde d'objets diyers. Elle rendra aux intéressés les tablcaux exposés dans la salle de la ci-devant Académie et que les auteurs ou leurs héritiers ont été autorisés à retirer par arrêté du Comité de salut public (3). Un ami de Hérault de Séchelles, Clouet, professeur à l'Ecole des mines, lui a prêté en prison une traduction de Shakespeare; il la réclame à la Commission, qui la lui rend (4). Louis XVI, comme par une dérision dn sort, avec quinze souscriptions, a gagné trois lots à la loterie des amis des arts pour 1792; ils sont là, qui attendent leur destination nouvelle (5). Plus lard enfin, quand la loi de l'an III rendra aux héritiers des condamnés la jouissance des biens saisis par la nation, c'est à la Commission temporaire qu'ils retrouveront tout sous le scellé.

On ne saurait trop louer l'œurre relativement obscure, mais éminemment utile, de la Commission des arts en ces temps oủ elle sut, à force de courage et d'abnégation, suffire à un immense labeur. Il ne faudrait pas croire qu'cn ce temps-là, et surtout avec l'idée qu'on se faisait du gouvernement révolutionnaire, c'est-à-dire, dans le langage d'alors, expéditif (6), les

(1) On est frappé du retour fréquent de ce mot laboraloire dans les locuments de celte époque, surtout quand depuis quelques années ii est tellement question d'en créer en France.

(2) 11 y avait parnıi res instruments une machine à diviser, que Léonard Bourdon avait demaudée pour sil maison de la Société des Jeunes Francais, installèe au pricure Saint-Marlin; mais on la jugea trop précicuse pour la meltre entre les mains des jeunes élèves. Lenoil offrit toutefois d'instruire un les éléves et le lui apprendre à diviser sur cette machine. Voir lRegistre de la Commission des arts, 20 et 25 floréal.

(3) Registre, 30 mes-idor.

(4) Registre, 15 prairial.

(a) Regristre, 20 thermidor.

(6) C'est ainsi quion fait des cours révolutionnaires sur la fabrication du salpétre; plus tard, en l'an I1I, Séguin tronvera le procédé révolulionnaive de tanner les cuirs. Nous lisons au registre de la Commission des arts, 
attributions des divers pouvoirs fussent absolument définies, et que la hiérarchie de leur subordination ou de leur compétence füt tonjours observée. Rien de cela n'existait, mais cet apparent désordre devint une source même d'activité et de puissance.

On n'a pas le temps de se consulter sur ses propres prérogatives et celles des autres : on agrit. 0 n se renvoie les uns aux autres les affaires par le plus court, et nul n'a la faiblesse de se sentir froissé. La Commission des arts dépend officiellement du Comité d'instruction publique, mais elle est en correspondance continuelle et directe avec les autres Comités, avec les ministres, puis les commissions qui les remplacent, avec les autorités de province, et même avec les représentants en mission (1). A force d'activité et de déronement à la chose publique, elle avait vu rapidement grandir son influence. A la fin de l'an II, elle rend des délibérations qui ont presque la valeur des arrêtés du Comité dinstruction, dont elle se détache de plus en plus et semble parfois même exciter le zisle. Ses rapports avec le Comité de salut public sont fréquents sans avoir rien de régulier. Tantôt elle est avisée par celıi-ci qu'en certaines villes, à Rouen par exemple, les monuments des arts ne sont point garantis et que personne ne s'en occupe (2). Un autre jour e'est la Commission qui sollicite, a son tour, du Comité des mesures énergiques pour mettre ordre aux déprédations qui se com-

10 prairial : "Sur l'exposé du citoyen Montamau, qui indique les moyens de former promptement l'établissement des tablettes pour le dépôt littéraire de la maison des Cordeliers, la Commission arrête que le travaildez tablettes dans ladite maison sera fail révolutionnairement et par urgence $\mathrm{D}$. - Les livres en ellet se détérioraient, la Commission avait écrit quatre lettres au département sans pouvoir obtenir cette menuiserie, et l'avait Inême menacé (30 floréal) de se pourvoir prẻs du Comité de salut public.

(1) La Commission écrit aıx représentants en mission a CommuneAllranchie pour les inviter á prendre des mesures pour faire mettre a l'abri les objets relatifs aıx arts diustruction, ainsi qu'aux arts mécaniques. Registre, 20 pluviôse.

(2) "Le présilent lait part d'une lettre du Comité de salut public, datée du 13 frimaire, concernant les objets relatifs aux arts existaut a louen, pour lesquels il n'y a personne qui veille à leur conservation. "liegistre, $\ddot{~ ̈ n i v o s e . ~-~ N o u s ~ t r o u r o n s ~ e n c o r e ~ u n e ~ l e t t r e ~ d e s ~ a d m i n i s t r a t e n r s ~ d u ~ d i s-~}$ tricl de Candol-la-Montagne, ci-devant Saint-Claude, avisant le Comité de salut public qu'on a trouvé un homme mort depuis mille ass, conservé par le mème hasard que quarante corleliers i Toulouse, et qui ne sert qu'à eutretenir la superstition. Cet homme mort n'est autre que saint Claude lui-mêrue. La lettre porte le cachet dı Comité de salut public avec cette indication: "Renvoyé au Comité d'instruction le 13 ventôse an $1 \mathrm{l}$ ", d'où la lettre alla á la Commission des arts (F $F^{47}$, carton 1307). 
me!tent à Douai (20 et 25 ventôse). Elle apprend (1) qu'on procede d la vente des animaux vivants qui existaient au lainey chez le ci-derant d'Orléans; clle décide aussitôt d'en aviser le Comité de salut public pourqu'ily mette ordre et qu'il cmpèche même la livraison des animaux vendus au mépris des décrets de l'Assemblée mationale, qui ont expressément ordonné de réserver pour la nation " tout objet pourant servir à son éducation intellectuclle (2) $)$.

Quand le Comité de salut public veut prendre les souffets d'orgues pour les forges de ses fabriques d'armes, la Commission lui remontre qu'il est nlus avanlageux de les laisser en place, parce qu'on risque, à les enlever, de détériorer les buffels (3). En même temps elle s'associc, pour conserver les jeux qui en valent la peine, un facteur dorgues de Paris; et tout d'abord, clle garantit, par une coúteuse cloison en planches, l'orgue de Saint-Germain des-Prés menaeé par les vapeurs de la raflinerie de salpètre installée dans la ci-devant église.

'Tout à coup ( 20 germinal) la Conmission apprend qu'on est en train d'enlever la couverture de plomb de Saint-Denis. Elle dépêche aussitôt Vandermonde, un de ses membres les plus marquants, aux informalions dans les bureaux du Comité de salut public, où on lui fait lire au registre un arrèté du $1^{\text {or }}$ ventose portant que toutes les églises couvertes en plomb et particulierement celle de la ci-devant ibbaye de Saint-Denis seront déconvertes. Il ne faut pas oublier qu'ì cette époque tout le fer de Paris avait été mis en réquisition, si bien que Chappe ne pourait pas mème s'en procurer pour ses machines télégraphiques; à plus forte raison on manquait de plomb pour les projectiles. Mais l'arrêté du $1^{\text {er }}$ ventose ajoulail que Saint-Denis serait recouvert tout de suite en tuiles on en ardoises, " aree la précaution de prendre des mesures pour que cette opération ne fassc éprouver aucunc dégradalion à l'édifice »; la Commission des armes el poudres était expressément chargée de ce soin (4). Un long rapport en date du 10 floréal nous montre en effet que tout s'étail passé pour le mieux, et que les dégradations avaient

(1) Registre de Ia commission les arts, $2 \ddot{\text { ventôse. }}$

(2) A la vélité, Richard et Thouin, qui avaient été délégués, pour cet objet, près du Comits de salut public, ne purent être recus, celui-ci "étant occupe d'objets de la plus hiute importance ", mais tout alla au mieux, le représcntant Crassons, statinnné da:ls le département, ayant donné les ordres nécessaires. Regristre, 18 ventôse.

(3. Registre, 10 germinal.

(4) Registre, 20 germinal. 
été à peu près nulles (1). A cette date toutefois, la Commission des armes el poudres, composée pourtant, elle aussi, d'hommes de science, n'avait point cxécuté jusqu'au bout les ordres qu'elle avait reçus et n'avait pas fait recouvrir l'église (2). A la vérité, le Comité de salut public, en messidor, la mettra en venle (3), mais il ne faut pas oublier qu'elle arait perdu à la fois depuis longtemps tout ce qui en faisait la richesse et la sainteté. Dès le $1^{\text {er aout }} 1793$ la Convention avait décrété la destruction des tombeaux; le 24 brumaire, elle avait accueilli «par les plusvifs applaudissements » une députation de la commune de Franciade (le noureau nom de Saint-Denis) lui apporlant les objets les plus précieux dı trésor de l'abbaye et la tête du saint.

Au milieu de tant d'oceupations, la Commission des arts trouve encore moyen de rédiger dès nivôse, el de publier cn ventôse, une fort longue Inslruction sur les moyens de conserver provisoirement les objets tombant aux mains de la nation. de les inventorier, de les cataloguer. C'est une brochure in-4. petit texte de 70 pages, où l'on trouve jusqu'aux meilleurs procédés pour conserver les peaux des animaux morts (4).

Cette Instruction est répandue partout. On apprend (15 messidor) que Romme, en mission, a établi, dans diflérents lieux, des commissions particulières ì l'effel de découvir les objets de science et d'art qui pourraient s'y trourer, et que ce représentant n'a d'autre désir que de se conformer aux procédés suivis par la Commission temporaire. On ne perd pas une si belle occasion de lui adressel l'Instruclion, dont quelques exemplaires viennent, d'être imprimés sur du papier refondu, car on manquait aussi de papier, et il avait fallu en refaire avec celui des anciens registres et titres (5).

(1) Archires nationales, $F^{17}$, carton 1048. Quelques parties vermoulues araient simplement fléchi. Les dégrats ne inontẻrent pas à 1,000 livres.

(2) Registre de la Commission des arts, 10 floréal.

(3) "Garrez, de Franciade, prévieut la Commission que, d'aprẻs un arrêté du Comité de salut public, on va procéder à la vente de la ci-devant église abbatiale." Registre, 5 messidor.

(4) Instruction sur la manière d'inventorier et de conscrver, dans toute l'étendue de la République, tous les objets qui penvent servir aux arts, aux. sciences et à l'enseignement, proposée par la Commission temporaire des arts et adoplée par le Comité d'ins!ructirn publique de la Convention nationale. Paris, Imprimerie nationale, an II. [Ln second tirage, qui fut fait cn messidor, contient, á la suite de l'Tustruction, un Rapprot sur la remise it la Cornmission temporuire des arts des cartes du dépouillement des ouvrages imprimés ou manuscrits, commencé it la Commission des monuments en 1790, signé Polrien et daté du 1 :j messidor an II. - J. G.]

(5) La citoyenne Masson avait proposé un procédé pour enlever limpres. 
Entre ces deux puissances, d'ailleurs fort inćgales, du Comité d'iustruction et du Comité de salut public, la Commission temporaire des arls, quoique dépendant du premier, se tourne résolument vers le second. C'est un très singulier caractère et très nel de l'époque de la l'erreur que celte gravitation des hommes de science autour du Comilé de salut public : lui-mème en tire groire dis avant le ? thermidor, et, après cette journée, les survivals sen feront tous un titre devant l'histoire. Au contraire, le Comité d'instruction publique est presque délaissé et ne joue, pendant toule cette époque, fu'un rojle secondaire dans les yuestions qui semblent direclement ressortir à ses attributions. Il ne faudrait pas croire cependant qu'il restât au-dessous de sa mission.

L'absence mẻme de Lakanal nous rend plus attentifs ì une foule de discours et de rapports présentés au nom de ce Comité par Romme, Fourcroy, 'Thibaudeau, Grégoire; nous ne citons que les plus connus. Le 29 frimaire, la Convention adopte le projet d'instruction primaire présenté au nom du Comité par Bouquier. Le 8 pluriose, à la suite d'un rapport présenté le 3 par Grégoire, elle ourre un concours pour la composition de livres élémenlaires ì mettre entre les mains de la jeunesse (1). C'est le 18 messidor, aux jours les plus sanglants de la Terreur, qu'elle nomme, sur le rapport de Thibaudeau, le jury qui derra les juger; Lagrange, Daubenton, Monge, Hallé, Vandermonde en feront partie, e'est-à-dire tout ce que la science possède de plus illustre. Les sourds-muets ne sont point oubliés : dès le 23 pluviòse, le Comité d’instruction publique a décidé de faire imprimer la méthode de l'abbé Sicard à deux mille exemplaires.

sion sans dénaturer le papier. La Commission des arts nommn Pelletier et llassenfratz pour saisir le Comité de salut public de cette méthorle nouvelle.

(1) Cette idée apparliendrait à la Commune, d'apris Michelet : roir IIistoire de la Rérolution, 18 brumaire. [Lidec d'un concours pour la composition des lirres ćlémentaires avait déjî été présentíc dans un rapport fait en 1792 par Arbogast au nom du Comité d'instruction publique. - J. G.] Le 3 ventóse, le Comité d'instruction publique, dans une sorte de dissertation qu'il adresse à la commune de libreville (Charleville), laquelle a consullé le Comité sur un nuvrage intitulé : Instruclion sociale ¿u républicain, - nous donne, en désapprourant cet opuscule, son opinion sur les qualités que doit avoir un livre élémentaire : "On n’y trouve pas ce qui caractérise un bon livre élémentaire: la régularité du plan, l'exactitude des défuitions, la justesse des pensies et la correction du style ". (Archives nationales, $\mathrm{F}^{17}$, carton 11 43 .) [La piece en question n'est plus dans le carton 1143, qui a élé remanié; il ne nous a pas été possible de la retrouver. - J. G. 
L'attention du Comité d'instruction s'était aussi portée sul l'enseignement supérieur, ou ce qu'on appelait alors le dernier degré. Il veut orçaniser les écoles de santé, établir quatre obselvatoires, eréer des bibliothèques, des cabinets de physique, des jardins botaniques (1). En réalité le Comité d'instruction représente l'esprit mème du xvıI siècle et l'Encyclopédie. Ses patrons s'appellent d'Alembert, Diderot, Helvétius; il procède d'eux (2), el tout montre que ses sentiments étaient alor's domiuants dans l'assemblée et surtout à la Nontagne, tandis qu'ils deraient virement déplaire aux Jacobins (3). On rit bien cet antagonisme lors du rapport de Robespierre sur les fètes nationales. La premic̀re sera celle " de l'Etro-Suprême et de la Yature »; les autres sont toutes consacrées aux passions qui ennoblissent l'homme, à l'amitié, à l'amour filial, à l'amour des époux et ainsi de suite. Les fêtes nationales étant essentiellement dans les attributions du Comité d'instruction, celui-ei, quelques

(t) [Rapport et projet de décrel sur le dernier degré d"instruction, présentẻ jar Bouquier le $2 \dot{z}$ gerninal. Ce projet fut ajourné. - J. G.]

(2) Ceci n'est exact que pour une partie des membres du Comité d"instruction publique, Roume, Arbogast, Guyton-Morveau, Fourcroy, Léonard Bourdon, lerry". On troure á côté d'eux, dans ce Comite, des prètres catholiques comne Grégoire. Villar. Coupé de l'Oise, un ministre rrotestant. Jay de Sainte-Foy, un ennemi déclaré des encyclopédistes, Petit, et plusieurs montagnards de nuance robespierriste, David, Bouquier, Mathicu, etc. - J. is.]

(3) C'est commettre unc erreur historique que de représenter la Société les Jacobins comme hostile à la philosophie des encyclopédistes. Elle comptait dans son sein des représentants narquants de ces doctrines. Elle choisit successivement pour présidents, de brumaire á thermidor an II. les hommes dopinions philosophiques assez diverses : Iontaut, Anacharsis Cloots, Fourcroy, Bouquier, Jay de Sainte-Foy, Reverchon, Thirion, Lavicomterie, Ch. Dural, Legendre, Veau de Launay, Lebas, Vadier, Voulland, Foucher, Louis, Barére, Elie Lacoste; mais Ies deux tiers au moins de ces nows sont ceux de personnages eu qui on ne saurait voir des adversaires de l'esprit du xwl siecle et de l'Encyclopédic. Si ellc expulsa de son sein Anacharsis Clouts. ce fut comme ètranger, non comme athée: au scrutin épuritoire, Iléhert. Momoro, Jeéonard Bourdon furent maintenus, tout comme Danton, Fabre d'Eglantine, Camille Desmoulins (ce dernicl fut exclu le 21 nirôse à cause des numéros du Vieux Cordelier, nais Robespierre obliut que la Société revint séance tenante sur le rotel. Le 19 horéal, an lendemain du rapport de Robespierre sur l'Etre-Supríne, il se passa au club des Jacobins deux faits bien caractéristiques : 10 La présidence de Lebas, ani personnel de Rohespierre, renait justement de prenuie fin; pour le remplacer, les Jacobins élurent Vadier, celui-lá méme qui derait un mois plus tard présenter is la Conrention le famenx rapport sur Catherine Théol, destiné á ridiculiser Robespierre et le culte de l'EtreSuprême; 20 Briral, aprés aroir rappelé que Lequinio arait, la reille, "reconnu la sublimité des principes que Robespierre a développés dans 
jours après, présente à son tour un projet (1) irsppiré de celui de Robespicre, mais dans un esprit tout différent. L'EtreSuprême a dispraru, la première fète sera celle « de la Nature » et rieu de plus. Un cerlain nombre de fètes restent consacrées aux nobles sentiments, mais les saisons ont leur part: enfin la dernière sera celle le "l'électricité ". Cependant l'influence de Robespicire l'emporte, et les membres du Comité d'instruction, qui araient bilfé l'Etre-Suprème, durent suivre dans la procession l'instaurateur du noureau culte (2).

son rappert ", fit olsserver cule ces principes ue s'accordaient pas avee deux ouvages publies par Lequinio, le Bonheur et les I'réjugés détruits, où l'auteul" "s'etforce de prouver qu'il n'existe point d'Etre-Suprème, et quaprés la mort tout est délruit ". Et quel accueit font les Jacobins á cette denonciation? Ils interrompent Brival par des murmures, et l'on passe it lordre du jour. Lequinio demaude à douner une explication "qui pronvera que la vertu est le seul mobile de ses actions ". On lui répond que c'est inutile, "la Société ayant dejà passé à l'ordre du jour, el témoigné par cetle conduite qu'elle n'exigeait aucune justitication de la part de Lequnio ". 11 est supertlu d'insister sur la signification d'une pareille démonstration. On renarquera en outre jue le choix des présideuts qui succéderent a Lebas, de Vadier à Elie Lacoste, témoigne bien clairement les préférences de la majorité. - J. G.]

(1) Projet de fétes nationales, présentè au nom du Comilé d'instruction publique, par IIATHEv.

(2) Nous sommes obligé de reclifier jei des erreurs matérielles au sujet du projet de fétes nationales présenté par le Comité d'instruction publique. Ce projet nest pas postrieur au rapport de Robespierre du Is tlorẻal : il lui est antérieur de plusieurs mois, et n'a pu, par conséquent, s'en iuspirer. Dés le 3 frimaire, le Comité d'iustıuction publique arait chargé une commission de six menbres de préparer un projet de décret sur les fétes nationales; ce projet lui fut présenté par llathieu, l'un des commissaires, le :̈ nirôse; le Conité le discuta dans ses séances les 13 et 21 nivôse ct 3 pluviòse, et arrèta, le 9 veulôse, que " pour mùrir son opinion particuliere, et à celte fiu pressentir l'opinion publique, le plan du rapporteur serait imprimé, et distrıbué aux unembres de l'assemblee, le Comitẻ se réservant de le soumettre i une discassion nourelle, dins uu court dẻlai, pour en citre ensuite présenté un rapport définitif el complet en son $10 m$ í la Convesution nationale ". Le projet de décret de Mathieu fut donc imprimé dans le courant de rentúse, sous ce titre: "Projel cle fétes nalionales, présenté au non du Comité d'ınstruction publique, par .lathieu, député du départenent de l'oise; à Paris, de llmprimerie nationale, l'an Il de la liépublique " cette piece est annoncée dans le no 536 du Junrnal les lebals el cles décrels, correspondant au 19 rentòse). En tête de la brochrere, on liten epigraplue un passage du rapport de liobespierre sur les principes de morale pulitique qui doivent guider la Convention dans l'aduinistration intẻrieure de la République, du 17 pluviòse, passage qui commence ainsi : "Nous roulons remplir les voux le la nature, accomplir les lestinées de l'humanité, tenir les promesses de la philosophie, absoudre la Proridence du long règne du crine et de la tyrannie ". l.article is dı projet le décret dit : a Ces files (décadaires), instituées 


\section{I}

Chose singulière, les Jacobins ne tiennent aucune place, absolıment aucune, dans l'histoire de l'esprit scientifique pendant l'époque qui nous occupe, quoique le club réunisse une foule dhommes qui ont au dehors une inlluence considérable sur les questions d'enseignement (1). Bouquier, l'auteur dı projet d'instruction primaire, Fourcroy, le chimiste Hassenfratz, Monze, sont assidus aux séances, ils sont élus au bureau (2), ils président (3), et, quand on procède à l'épuration successive des

sous les anspices de l'Etre-Suprême, auront pour ohjet de réunir tous les citoyens, de leur retracer les droits et les devoirs de l'homme en socièté, de Jeur faire chérir la nature et toutes les vertus suciales "; et les arlicles 7 el 8 ajoutent : "Ces réunious fratermelles et périodiques auront lieu dans les édifices nationaux consacrés à un culte public... Ces édifices serout tous appelés Temples de la Raison ". On ue sıurait donc dirr, ou le voit, que du projet de Mathieu et du Comité d'instruction publique "l'EtreSuprème a disparu ", que "les meubres du Comité d'instruction avaient biffé l'Etre-Suprême "; ceux-ci y avaient au contraire écrit ce nom longtemps avant que Robespierre l'eùt prononcé dans son lapport.

Le 11 germinal, le procès-verbal du Comité d'instructivn publique nous apprend que le Comité "autorise Mathieu it se concerter avec le Gumité de salut public ponr le projet de décret sur les fêtes nationales ". Le résultat de ce concert fut que le Comité de salut public retint le projet, pour s'en réserver l'initiative, et chargea liobes jierre de préparer un rapport sur cet objet. On doit donc dire, pour être exact, non que le Cumité d'instruetion publique présenta un projel inspiré de celui de Rohrspicrre, mais, au contraire, que le projet présenté par Robespierre le 18 floréal avait été in:piré, pour une part du moins, par celui du Comité d'instruction publique. (Robespierre a einprunté au projet de ce Comité le titre de vingt et une des treute-six fètes décadaires décrétées le Is lloréal.)

Dètail curieux à notel : après le 9 thermidor, Mathieu reprit, en son nom personnel (il ne faisait phus partie dı Comité d'instruclion publique), le projet de ventôse an II, et le fit imprimer de nouvean, en nirûse an JI, avec quelques modifications. Les fèles sont toujours instiluées a sous les auspices de l'Etre-Supreme ", mais le Temple de la Raison est devenu le "Temple décadien "; quant à l'épigraphe empruntác a liobespicre, elle a naturellement disparu : Mathicu la remplacée par unc phrase insignifiante de labbé Raynal. C'élait, on le sait, 111 aprêté du Cimilé dle salut public du 23 lloréal an II, rendu à la suite d'une pétition du Conseil général le la commune de Paris, qui avait ordomé que l'unscriplion 'lemple de la Raison serait effacéc du frontispice des édifices ci-devant consacrés au culte : les thermidoriens se gardèrent bien de la rétablir. - J. G.]

(1) [Est-il besoin de rappeler que la Société des Jacobins étıit un club politique, qui n'avait pas pour objet de s'occuper de questions de science? - J.G.]

(2) Monge est élu secrétaire le 29 nivôse, et plus tard vice-président.

(3) Fourcroy est président des Jacobins du 11 au 26 frimaire. Il a pour successeur Bouquier. 
membres, au moment oil commence la lutte de Robespierre et de Danton, tous ces hommes de science " sortent purs du creuset des épreures ». Et pourlant, malgré leur autorité dans Ia Société, celle-ci ne met jamais à l'ordre du jour nne seule question touchant amx sciences et ì l'instruetion. L'esprit qui l'anime avant tout est celui de Rousseau. Pour les Jacobins la grande affaire, e'est l'éducation. Aussi quand Bouquier vient y lire (le 21 frimaire) son projet d'instruction anquel la Convention vient d'accorder la priorité, voyons-nous Hassenfratz dire qu'on donne trop de place aux sciences. Dufourny rencliérit et veut pour tous un système égalilaire, dont on retrouvera l'esquisse dans un travail déposé à la Conrention pendant les premicrs mois de 1793 par Robespierre, et ou il y a encorequelques bonnes choses (1). Mais, depuis celte époque, il est évident que l'esprit jacobin s'est replié sur lui-mème, et que nous tendons de plus en plus à ce système antiphysiologique dont Saint-Just trace le plan dans ses Institutions, laissant les filles à la maison, tandis qu'on embrigade tous les enfunts miles de six ans pour les soumettre a une vie uniforme qui semble inspirée moins encore des sourenirs de Sparte que des règles monastiques.

A tout prendre, l'hébertisme a ici l'arantage sur les doetrines en vigueur aux Jacobins. Quand Bouquier a fini de lire son projet, le membre du club qui applaudit avec le plus de chaleur est Hébert. Il félicite la Convention d'aroir, comme autrefois le sénat romain vendant le champ d'Annibal, fixé l'établissement d'une école de génie à Valenciennes qui est encore au pouvoir de l'ennemi (2). Il demande que là Société, pour s'occuper dignement d'un sujet aussi intéressant que l'instruction publique, mette continucllement ì l'ordre du jour le plan qui vient de lui être proposé.

Hébert parlait dans le désert. Dans cette société d’hommes distingues, linstruction publique excitait certainement moins

(1) [Il est probable que c'est du plan de Lepeletier, lu à la Conveution par Robespierne le 13 juillet 1793, que G. Potuchet veut parler ici. - J. G.]

(2) [tl ne fiulliait pas que les paroles d'llebert fissent croire que la Convention aurait en ellet rendu ce jour-lá un décret relatif aux écoles do génic. L'asscublée avait simplemeut, le 2l frimaire, accor lé la priorité an projet de décrel de lionquier, formant un plan général d'instruction jubtique. Ce projet compreuait cinq sections; et l'alticle 4 de la section IV provogait l'établissement de quatre écules de ginie et d'artillerie, dont une a Valenciennes. Les trois prenteres sections du projet furent seules votées, et fomerent le décret du :29 frimaire. (Quant aux deux delnières, présenlées le nonveau le 2 ǵ germinal, elles furent indéfuiment ajournées. - J.G.] 
les esprits qu’à la commune, qui elle-méme ne vit r'ien au delà de l'école primaire. Dès le 27 septembre, Chaumette arait fait abolir les peines corporelles dans les maisons d'éducation. Il a son système sur la manière d'élever les filles, le même que Molière faisait applandir à la cour de Louis XIV dans le personnage des fiemmes savanles. Chaumette recoit fort mal, un jour, quelques femmes qui s'étaient affublées du bonnet rouge, " emblème viril des sans-culottes 》. Le 21 pluviôse (1), une mère présente à la commune sa fille âgée de six ans, qui vient réciter des vers. Elle s'en acquitte, parait-il, assez bien, et quelques applaudissements semblent encourager le petit prodige. Mais le président fail remarquer que telle n'est peut-ètre pas la bonne roie pour élever les jeunes citoyennes. La mère, qui est jolie, insiste et veut défendre le précoce talent de la fillette. Chaumette alors se lère, excuse la mère qui a cru bien faire, mais ill'engagre plutòt à apprendre à son enfant à faire des bas. "Lorsqu'elle en aura tricolé une paire, dit-il, rous la ramènerez ici, et nous en arrêterons mention civique. ) Les détails donnés tout au long dans les journaux du temps prourent l’importance qu'on altache à l'incident.

Cloots n'était pas moins décidé sur la question de l'instruction primaire que Chaumette ou Hébert. Et si ces trois noms se trouvent ici réunis, quon n'y roie point d'autre intention que celle de grouper tous les documents qui nous sont restés sur les opinions des chefs d'un même parti. Cloots était membre du Comité d'instruction; daus l'Opinion sur les spectacles, qu'il pubiia en nirôse, il appelle l'instruction « une étolle de première nécessité dans un pays libre (2) ). Il raconte, dans une note. comment il avait vu par une belle journée d'automne deux jeunes sans-culottes étendus sur l'herbe des Champs-Elysées, avec un live, et qui se servaient mutueliement de mentor. Il s'approche, interroge les gamins qui lui font une réponse, en grands mots empruntés à quelque orateur de section, sur la nécessité de l'instruction dans un pays libre, "et nous roilit tous trois, ajoute Cloots, criant ì tue-téle: Vive la République?») Yous ne nous serions pas attiché à celte anecdote connue si un

(1) Vuir le Journal de la llontayne.

(2) Instruction publique : Spectacles, Opinion d'Anacliarsis Clools. membre du Comité d'iustruction publique. "Jen conclus que nous établissiuns des écoles militaires, des écoles de musique et d'équitation, des écules de marine et de médecine, des bibliotheques publiques, des cabinets de physique, des laboratoires de chimie, des jardins de botanique... " 
rapport de police (1) ne donnait textuellement quelque temps après (2l ventôse) ce lémoignage d'autant moins suspect qu'il est plus étranger a la politique: "De tous cótés on demande l'établissement des écoles primaires; la jeunesse a beaucoup de disposilions ì receroir les éléments du républicanisme ». Cloots, comme Hébert et Chaumette, n'était donc que la voix de ce grand Paris, qui avait soif d'instruction (2).

Comment ceci s'accordait-il avec la scuerre déclarée de toutes parts aux monuments? Le grand crime des hébertistes, de la commune, des seclions, des socićtés populaires fut l'ignorance. Elle éclate à chaque instant, et, si elle n'est poiut une excuse, elle doil du moins nous faire prendre en pitié plutôt qu'en haine ces hommes laissés, par le régime passé, dans un abètissement dont la Convention faisait à ce moment mème un suprême effort pour les tirer. Le peuple, ne sachant pas la valeur des choses, n'en voit que la signification; si elle le blesse, il délruira pour faire disparaitre lá source d'une impression désagréable (3). Qu’on y réfléchisse, on verra que rien n'est plus logique. Nous en parlons bien à notre aise, connaisseurs qui sarons voir à la fois dans un objet d'art et ce qu'il représente, et la main qui l'a fait, et l'époque qu'il rappelle. Mais nous somines fous de vouloir les mêmes délicatesses chez ceux dont la misère, le travail grossier, l'ignorance, ont privé les sens de la mème finesse.

Le peupie de la Rérolution s'en prend a tout ce qui signifie à ses yeux royauté, féodalité, superstition. Mais cette manic de détruire ne fut jamais un systime, elle est instinctive, tout

(1) Voyez A. Scmund, Tableaux de la kévolution, Leipziğ, IS69, t. Il, p. 14 '́.

(2) Le 9 floréal, la commune nomma une Comuission centrale de surveillance des écoles primaires. - On lira avec intérèt, dins la séance du Conseil général de la commune du $2 S$ germinal (Vuir le Journal de la Monlagne), me diatribe de Jault contre un livre "bète, piloyable, dégoùtant, intitulé Journal de laulre monde. Les pires de fauille rechercheront des livres où linstrucion est basce sur le respect pour la replésentation nalionale. Ies mours! s'ecrie-t-il, quelles soleut i jamais rotrp risgle! ”

(3) On avait étibli au château d'Econen une ambulanre; la Commission militaire, sur la plainte des malades qui commençaient a murmurer, écrit i la Commission des arts, Je 26 messidor, pur fare cnlevel prouptemeut des vitraux, où s"offrent des " restes deföudalite et de fanatismequi

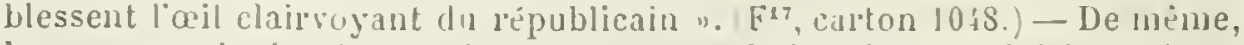
la commune invite, le 1 i frimare, la Commission des alts i faire enlever les tableux et monumeuts précieux existant daus le temple le la Raison, ci-deraut église métropolitaine, " parce quil est trés essentiel que des yeux républicaius ne soient plus ofỉnsqués par ces restes scaudaleux du lanatisme". 'li:, carton 1045.) 
individuelle, elle dépend des circonstances et se modifie. Au commencement du second mois, la commune fait jeter à bas toutes les statues du porche de Notre-Dame, sans doute parce qu'elles ont une eouronne sur la tète. En pouvait-il être autrement quand, ì ce moment même, les journaux comme le Moniteur, lus par la classe la plus éclairée, déclarent qu’on ne saurait jouer aux échecs? Les trésors des chapelles ne sont pour la commune que des " hochets d'égrlise (I) ); mais on sait aussi avec quelle complaisance la Convention reçut toujours ces sortes d'ofirandes patriotiques, quoiqu'elle eût à plusieurs reprises rendu des décrets pour protéger les monuments, les livres, les gravures qu'une lleur de lys dans l'écusson de la dédieace suffisait à faire jeter au feu. La Commission des arts, de son côtó, se multiplie, elle a l'œil à tout. Elle cherche à gagner du temps avec les administrateurs du district de Franciade qui veulent démolir les clochers de la ci-devant abbaye (2). La sociélé populaire de Loudun rève aussi de détruire " tous les clochers et autres objets élevés qui peuvent servir de ralliement alix brigands qui infestent la Vendée et qui présentent des signes de superstition et de eatholicisme ». La Commission renvoie la lettre à la Commission des poids et mesures, "chargée spécialement de la destruction ou conservation de ces corps élevés, selon le degré d'utilité dont ils peuvent être pour les observations météorologriques (3) ". A l'inverse, certains districts demandent des renseignements sur la valeur d'objets d'art et s'informent s'il les faut conserver.

A Paris les rapports de la Commission des arts aree les sections diffèrent selon le tempérament de celles-ci; dans les unes elle trouve des auxiliaires déroués; d'autres lui donnent fort à faire. Le comité civil de la seetion du Muséum, quand on va transformer le temple de la Raison, ci-devant Siaint-Germainl'Auxerrois, en raffinerie de salpêtre, éerit à la Commission des arts de faire enlever les grilles du chour, « monument précjeux et propre à faire connaitre dans tous les temps le haut degré de

(1) Dans un arrité du ts brumaire sur les objets pieux des églises, il n'est absolument question de ceux-ci qu'au point de rue du poids du métal. ( $\mathbf{F}^{17}$, carton J0.8.) Plus tard, toutefois, les idées de la commune sur ces matiẻres se modifient, sans allcun doute sous lintluence des décrets rendus par la Convention pour précerver les objets d'art.

(2) La question de la destruction des clochers avait été déji autéricurement agitée au sein de l'Académie des sciences. Voy. Bertmax.

(3) llegistre de la Commission des arls, 23 prairial. 
perlectionnement auquel les artistes ont porté l'art de trarailler le fer (1)).

Le comité rérolutionnaire de la section de Chalier va célébrer dans l'église de la Sorboune une fête en l'houneur de la victime lyonnaise. Il fait prérenir la Commission des arts d'avoir ì enlever les marlores qui peuvent y rester encore, afu de prévenir toute destruction aveugle. Nous avons, quelques jours après, la preure que telle était bien la pensée du comité. Un tableau a élé mutilé, trés probablement pendant la fète. Le comité rérolutionnaire s'empare de l'affaire et adresse à la Commission des arts un extrait de son proces-rerbal, alin qu'on puisse juger de l'importance du délit et le dénoncer, s'il y a lieu, aux autorités qui en doivent connaitre. La Commission félicite le comité de la section de Chalier de son zèle, et l'informe qu'heureusement cette toile n'élait qu'une copic (2).

Beaucoup moins traitable (3) fut la section du Bonnet-Rouge (Croix-Rouge), qui arail fail de Saint-Sulpice un temple à la Plilosophie. On arait enlevé un certain nombre de statues et de marbres, mais d'autres furent brisés sans que la Commission des arts eût pu l'empècher. Nous la trourons aussi fort inquiète au sujet de la méridienue tracée en 1743 sur le paré de l'église par l'astronome Lemonnier. Celte méridienne passe sur les marches du maitre-autel. On arait commencé de les démolir : la Commission demanda au Comité un sursis, pour qu'on pût au moins prendre des repères afin de tracer exactement la méridienne à la place des marches (4). Déjà, au début de l'année, la Commission des arts avait eu un autre souci. Il s'agissait des deux grandes ralres de Chama gigus qui servent de bénitiers, et

(1) Extrait du regi-tre des délibérations du comité civil de la section du

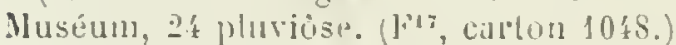

(2) Registre le la Commission des arls, 30 messidor.

(3) Un témoignage, postiricur i la vériti au 9 thermidor, noms montre que la section de l'olservatoire itcit fort peu rommode. Nonet, astrornome de l'Observatoire, dénonce, le J fructidor, a la Commissinn des arts Ruclle, wembre du comilé révolutionnaire de la section; " un lui reproche son ignurance crasse, el les moyens de persécution qu'il a employüs contre des sarants, membres de loubservatoire, ses collèrues ". [La dénonciation de Numet ne prouve rich que son animusité contre Ruelle, qui était l'uu des quatre atronomn:s de l'observatoire. Hom Nontet était un ecclésiastique cunemi de la Révolution. Ruelle était mu patrote exalté. - J. (i.]

(4) Registre de la Cummission des arts, 10 rerminal. Le Comilé d'in-

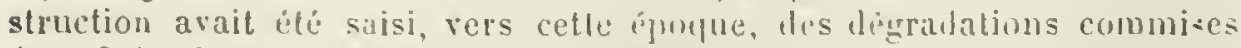
dans Saint-Sulpice et avitil anforise Mullard, membre de la Coumission,

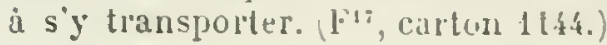


qu'on voit dans l'église, de chaque còté de la première colonne, portées sur des pieds de marbre sculptés (1). C'était à la fin de brumaire, la section allait célébrer une fête de la Philosophie. La Commission des arts craint que la foule ne compromelte les deux précieuses coquilles, elle charge Lamarck, professeur au Muséum, de veiller à leur déplacement; et c'est de sa main que nous sarons comment les choses se passèrent. Il se rendit à l'église, accompagné des commissaires du pouroir exéculif et de ceux de la Commission. Après avoir constaté que les coquilles étaient en bon état, on voulut les enlever, mais c'était tout un trarail, elles tenaient solidement scellées au mur; on ne troura pas d'ourriers ou ils n'eurent point le temps, bref le soir arriva et les denx bénitiers étaient encore en place. Alors Lamarck prend deux bandes de papier et il y écrit en grosses lettres: "Respect aux propriétés nationales», et les colle sur les coqtilles avec le cachet de la Commission des arts. Puis, comme cette injonction toute platonique aurait pu ne pas suffire, il s'adresse au comité de surreillance de la section pour qu'on metle des sentinelles. Et c'est ainsi que les soldats de l'armée rérolutionnaire ont gardé les bénitiers de Saint-Sulpice pendant la fête de la Philosophie (2).

\section{IV}

Il est très difficile d'apprécier quel était alor's l'esprit dans la province et jusqu'à quel point elle s'associa à cette croisade contre lous les emblèmes des idées du vieux monde. Les histoires locales font défaut. Autant qu'on en peut juger, les départements offrirent le même contraste de barbarie ignorante et de bonne volonté qu'on trouvait dans les sections de la capitale. Mais il est certain, d'autre part, qu'ils reçurent le contre-coup de l'activité scientifique qui dérorait Paris. Les manufactures d'armes créées par le Comité de salut public, les musées, les

(1) L'année suirante, la commune d'Annonay derait offrir deux coquilles aussi grandes, celles-lả même, croyons-nons, qui sont actuellement au Muséum, de charue côté de lhorloge apportée de Trianon ( $\mathrm{F}^{17}$, carton 1.29.)

(2) Nous avons le procés-verbal de toute cette affaire (F $F^{17}$, carton 1224 ). lous appreuons, d'autre part, que ce rapport fut déposé à la Commission des arts le 10 frimaire, et qu'en outre, ḋ cette date, le comité révolutionnaire de la section du Bonnct-Rouge arait fait desceller les coquilles, qui furent transportées dans un dépôt national. (Registre de la Commission des arts, 10 irimaire.) 
bibliothèques, les jardins botaniques vout faire pénétrer les connaissances scientifiques, ề le nom des sarants à qui on les doit, juscqu'an fond des districts.

La Convention, par denx décrets successifs du 16 et du 22 germinal, annonce le projel de créer dans les départements des bibliothèques et des jardins botaniques. Par le second, rendu sur le rapport de Grégoire au nom du Comité d’instruction, elle presse l'inventaire de tous les livres devenus la propriété de la nation (1). Par le décret du 16, elle enjoigrnait aux administrateurs de districl " de constater l'état des jardins et des plantes rares qui ponrront s'y trouver, et de prendre sans délaj les plus actires mesures pour leur conservation provisoire et Jeur entrelien ». Peu de temps après, les Comilés d'instruction el des domaines réunis adressent i tous les districts un questionnaire pour aroir des rensei -nements sur ce qui a été fait et ce qui existe. On y demande enlre autres choses s'il se fait dans ces jardins " des observations méléorologiques». La météorologie, qui attend anjourd'hui encore en France un enseignement officiel (2), et qui n'a que depuis quelques années ses établissements spéciaux, préoccupait rivement les hommes d'alors, qui en auraient cerlainement fait une science loute française, si les traditions de cette époque ne s'étaient presquaussitôt perdues.

Le 15 floréal, le Comité de commerce, à son tour, propose à la Convention un décret organisant un jardin des plantes dans chaque département (3). Le triple but quion doit se proposer est très bien défini : "science, culture, acclimatation ". Ces jardins derront servir ì inspirer le goùt de la botanique, à multiplier les végétaux utiles, à introduire dans l'usage les espèces étrangères. On semble hésiter cependant entre cetle destination plus particulièrement scientifique et des espèces d'écoles agronomiques qu'il est aussi question de fonder sous le nom de Métairies nationales (4).

(1) Rapport de Grégoire sur la bibliograpbie, 22 germinal an Il. - Déji le 8 pluriôse, sur le rapport fait par Coupé an nom du Comité d'instruction, la Convention arait décrété que les bibliothẻques seraient établies dans tous les districts.

(2) [Ceci était écrił en 1873. - J. G.]

(3) Rapport et projet de décret relatif i l'établissement des jardins des plantes dans les dipartements, par Boiscet, 15 Iloréal an 11.

(4) Nunveaux léveloppenonts sıl' l'établisscment de maisons d'économie rurale, par Grégoire, 16 brumile an II. - P'ar décret du 12 prairial, la Convention orlonne que lia lásorerie tiendra a la disposition de la Commission d'agriculture la som:ue de 150,000 lirres, pour les dépenses néces- 
Il y avait à Courset, près de Boulogne, un ancien noble du nom de Dumont, qui possédait un fort beau jardin botanique avec des serres où l'on royail des plantes qui n'existaient pas dans celles de Paris. Ce jardin passait pour le second de France. Mais Dumont avait été compris comme ex-noble dans une mesure générale prise par Saint-Just et Lebas en mission à l'armée du Nord; on l'arait jeté à la prison des Ursulines de Boulogne. Sur ces entrefaites voilà qu'on lui adresse une caisse de plantes rares, et pour comble d'infortune il fait un temps superbe, qui menace les jeunes pousses. Dumont fait part de ses inquiétudes aux administrateurs du district révolutionnaire. Ceux-ci, dans leur séance publique el permanente du 6 floréal (1), discutent l'affaire et décident de s'adresser direclement à Paris au Comité de salut public, pour demander l'élargissement du citoyen Dumont, qui est estimé de tous et qui passe d'ailleurs (grande recommandation) pour avoir dépensé une partie de sa fortune " à former une collection utile a la patrie, tant pour la partie spécialement bolanique que pour l’agriculture en général ». On allègue le récent décret de la Convention (16 germinal) qui ordonne de veiller a l'entretien des jardins botaniques, en ajoutant que personne dans le pays n'est en mesure de donner aux plantes du citoyen Dumont les soins qu'elles réclament. On décide en outre qu'en attendant la réponse de Paris, on va mettre Dumont en liberté provisoire pendant une décade sous la surveillance d'un garde qu'il paiera; on lèvera chez lui les scellés de la salle à mangrer et de la chambre qu'il doit occuper arec son garde, puis cclui-ci le ramènera au bout de dix jours pour être, s'il ne survient pas d'autre décision, "réintégr'é dans la prison des Ursulines au nom de l'intérêt général ». L’alTaire à Paris traina dans les comilés jusqu'en messidor (2), mais déjà la Commission des arts avait enroyé à Boulogne un agent (3)

saires à l'entretien des jardins botaniques et des plantes rares des diver's districts.

(1) $\mathrm{F}^{17}$, carton 1225

(2) Voyez le rapport an Comité de salut public, F17, carton 1220. Le projet primitif prrrait la proposition de mise in liberlé, mais on décida de demander préalahlement l'avis du Comité d'instruction publique.

(3) Cet agent élait le nommó Tiesset fils, employé dans les bureaux de la Commission. Les instructions qu'il emporte sont intéressantes : "Il avisera á conserver la collection Dumont, mais, en méme temps, il s"informera du noubre des livres d'émigrés, de ci-devant couvents, et autres qui pourront appartenir à la nation. II pressera autant qu'il sera en lui la confection des calalogues et se fera remettre ceux qui sont déjá faits; il prendra connaissance des monuments publics, des objets relatifs à l'bis- 
pour veiller à la conservation des plantes rares, tandis qu'elle s'employait à faire mettre Dunont en liberté. Elle réussit, et le $1^{\text {er }}$ thermidor l'amateur de jardins lui éerit ses remerciementes (1); il ne garda pas rancune à la République, et nous le retrouvons, à peine en liberté, préparant des boutures et des graines pour les jardins botaniques qu'il sera de nouveau question en l'an III de créer dans les départements.

Si Saint-Just et Lebas araicut failli compromettre les richesses botaniques de Dumont, d'autres représentants en mission, sans attendre les décrets de l'assemblée, avaient favorisé de tnut leur pouroir la eréation ou le développement de ces jardins botaniques, qui étaient alors comme un besoin de l'époqne. Fouché, Fouché lui-mểne, arons-nous dit, en mission à Nevers dans le courant de septembre 1793, met en réquisition l'cnclos des ci-derant Minirnes, pour faire un jardin botinique où il place un directeur et un démonstratenr (2). Lakanal est envoyé à Bergerac installer une manufacture d'armes. Il crée, lui aussi, un jardin bolanique, et rien n'est assez grand, à son gré, pour l'école d'économie rurale qu'on y doit placer. S'il n'y a point encore de cours de botanique, c'est qu'on n'a pas trouvé de botaniste dans le canton. Il n'y a pas d'orangerie, mais on transportera celle d'un émigré du voisinage; on apportera aussi tous les livres relatifs aux sciences naturelles, provenant des ci-devant chateaux de la Force et de la Pile. Il y aura également un cabinet d'histoire naturelle, car rien ne doit manquer à l'instruction; déjà l'herbier contient 4,090 plantes et augmente chaque jour. On a fait venir de Paris un jardinier que Daubenton a aussitôt enroyé. Enfin on a installé un rucher dont le miel - détail charmant -- est destiné à l'usage des malades

toire naturelle, aux collections précieuses, il la minéralogic el en général de tous ceux qui peuvent itre relatifs aux attributious de la Commission. A ces instructions est joint une sorte de passeport arec le signalement de Tiesset. Le 26 messidor, Tiesset écrit qu'il est arrivé le 23. qu'il ra aller voir la collection de Dumont qui vieut d'être mis en liberté ll ajoute: "L'instruction publique est en général très négligée: les iustituleurs sont en général peu instruits, j"ai remarqué sur cette partie plusieurs abus sul lesquels je me propose de vous faire un rapport. La souscription pour le charbon a été accueillie arec ce saint enthousiasme qui caractérise les amis de la République... " (F1;, carton 12.29).

(1) lus lettres de Tiesset nous apprennent que Dumont arait été mis en liberté dés avant le 26 inessidor par ordre du Comité de salut public, sur la demande de la Commission d'agriculture ( $\mathrm{F}^{17}$, carton 1229).

(2) Arrété pris le 23 septembre 1793 sur la réquisition dı représentant du peuple Fouché $(\mathrm{F} 17$, carton 1225). 
de l'Hospice. Il n'existe encore aucun bàtiment, mais cela ira vite, et quatre citoyens "d'un patriotisme reconnu ) sont nommés d'avance pour régir l'établissement sous l'œil de l'administration. Tout cela est organisé; les constructions sortent de terre à vue d'œil; les murs ont déjà cinq pieds quand éclate la révolution de thermidor. Deux ans plus tard, sous le gouvernement des thermidoriens, tout était encore au même point à Bergerac (1) et à Nerers (2). Les fondations de Fouché et de Lakanal étaient sacrifiées à l'esprit nouveau.

Le Moniteur du 8 septembre 1793 annonce la mise en vente de la $57^{e}$ livraison de l'Encyclopédie par Monge, Fourcroy, Cassini, Duhamel, etc. Le mème numéro contient les discour's de Barère, de Billaud-Tarenne et du pasteur Jeanbon Saint-André rlemandant à la Convention, dans la séance du 5 septembre, de "placer la Terreur à l'ordre du jour ». La Rérolution jusqu'à cette époque n'avait point interrompu le progrè̀s des sciences. Le Comité de salut public va les exciter encore pour sauver la patrie. Híais le goút même des sciences ne fut point paralysé dans le public par ce régime que nous considérons en arrière de nous avec tout leffroi qüil inspirait alors aux ennemis de la Rérolution. En pleine Terreur nous royons éclore une revue scientifique et littéraire, la Décade philosophique, qui virra jusque rers l'an $\mathbf{X}$ et où l'on troure quelques travaux de valeur. Elle commence de paraître en floréal an II et poursuit au milieu des événements sa paisible propagande. En messidor, au moment où la loi de prairial a tout à coup donné une si terrible impulsion au système de gouvernement par la terreur, la Décade publie des dissertations sur la récolte du miel et l'exploitation des ruches. Le 5 thermidor, l'article principal est sur le sommeil des plantes. On se eroirait au temps des Géorgiques et des rustiques loisirs, si vingt fois dans le courant

(1) Voir lettre du 17 prairial an $1 V$ et réponse du district au questionnaire sur les jardins botaniques (F17, carton 1223.)

(2) Dẻs le 9 fructidor, la Comnission exécutive de l'instruction publique avait refusé de conserver la crẻation du jardin botanique, en allégnant la lettre du décret du 16 germinal, laquelle dit simplement : "Lis alministrateurs de districts constateront l'état des jarlins ou des plantes rares qui se trouveront dans leurs jardins respectifs. Elles prendront sans délai les mesures pour activer leur conservation provisoire et leur entretien." 
du premier volume et jusqu'à la dernière page ne revenaient, au bas d'arrêtés intéressant les sciences et les établissements scientifiques, les noms des membres du Comité de salut public.

Les Annales de chimie avaient cessé de paraitre en juillet 1793, avec le dix-huitième volume. Lc dix-neuvième ne fut publié que trois ans après, en l'an V, \& par les citoyens Guyton, Monge, Berthollet, Fourcroy, Adet, Séguin, Vauquelin, Pelletier, C.-A. Prieur, Chaptal et Van Mons ". Dans l'avant-propos ils disent que "la nécessité de s'occuper uniquement de la défense de la République, les événements de la Révolution, enfin les occupations et les fonctions publiques des auteurs sont les causes naturelles de cette suspension ". En un temps où chacun jetait l'anathème aux vaincus de thermidor, les nonveaux éditeur's des Annales n'y songent point. Et en vérité comment l'eussent-ils fait? Le volume commence par la réimpression d'un Mémoire de Vandermonde, Monge el Berthollet sur la fabrication du fer, " publié par ordre du Comité de salut public " au commencement de l'an II. Quelques pages plus loin, c'est un travail sur un procédé pour extraire la soude du sel, également publié en messidor par ordre du mểme Comité.

Le Comité de salut public fut en effet l'âme d'une somme prodigieuse de travaux scientifiques accomplis. Il eut ce sentiment très net qu'il vaincrait par la science; il sut l'employer; il eut un mérite encore plus rare chez les gouvernements, il s'en fit gloire. De là ce caractère particulier des sciences à cette époque d'avoir été tournées uniquement vers l'application, soit pour activer les grandes entreprises déjà commencées, soit pour créer de nouvelles merveilles, comme l'industrie du salpêtre, la fabrication des canons, l'affinage de l'acier.

L'histoire de l'aérostation appliquée à la guerre appartient entièrement à l'époque qui nous occupe. Dès le 4 du second mois, le Comité de salut public arrête qu'un ballon capable de porter deux hommes sera préparé pour l'armée du Nord; il affecte à ce service une dépense de 50,000 livres et charge de l'organiser les citoyens Coutelle, Conté et Lhomond (1). Le Comité, moins encore que Louis XIV, n'avait coutume d'attendre (2) : tout doit être prêt sous huitaine. Ainsi fut fait. Quatre

(1) [Cet arrêtẻ est imprimé dans le Recueil des actes du Comilé de salut public, de M. Aulard, t. VIII, p. 3. - J. G.]

(2) Le 19 du premier mois, la Convention avait rendu le déeret suirant : "L'inertie du gouvernement étant la canse des revers, les délais pour l'exécution des lois et des mesures de salut public seront fixés. La violation des délais sera punie comme un attentat à la liberté. " 
jours après, Coutelle part, et le 14 brumaire le ballon le suit au quartier général de l'armée combinée du Nord et des Ardennes.

Qu'arriva-t-il? Le 4 frimaire, Coutelle est déjà revenu rendre compte d'un essai infructueux qu'il a fait, et il demande de nouvelles instructions. Le Comité ajourne l'usage des ballons à la prochaine campagne avec ce remarquable considérant : «que les obstacles apportés par la saison pourraient faire prendre des accidents pour des difficultés insurmontables ». On transporte l'aérostat au Petit-Meudon, afin de se livrer à de nouveaux essais, et l'on prépare tout pour la nouvelle campagne. On se sourient alors que le général Meusnier, tué à la défense de Mayence, a dủ laisser un mémoire manuscrit sur les avantages qu'on peut tirer des ballons à la guerre. Il faut à tout prix retrouver ce document. Le comité de la section Mutius Scævola est chargé de faire une perquisition dans la maison qu'habitait Ieusnier; on ne découvre rien. Carnot dépêche alors au commandant du génie de Cherbourg l'ordre de fouiller un logement qu'occupait dans la ville le savant officier avant d'être dirigé sur la frontière. En mème temps, on fait fabriquer à Lyon des étoffes de soie inconnues jusque-là, qui réuniront les conditions de légèreté et de solidité voulues. On fait chercher à Dijon deux nacelles ayant déjà servi, qui doivent exister à l'Académie de cette ville. Enfin on organise à Meudon une compagnie d'aérostiers, qui apprennent militairement la manœurre des ballons de guerre (1).

Le $1^{\text {er }}$ floréal tout est prêt, et Coutelle se dirige avec son ballon sur Maubeuge, où durent aroir lieu les premières ascensions. Deux mois après, l'aérostat s'élevait sur le champ de bataille de Fleurus ( 8 messidor). Le représentant Guyton le montait avec un officier nommé Lamet. Au dire de M. Louis Blanc, Jourdan, dans ses mémoires, aurait écrit «que le ballon fut si peu utile que depuis on n'en a plus fait usage ). Les faits donnent un démenti formel à cette assertion. Jourdan lui-même perdit à Würzbourg un ballon cui figure encore parmi les trophées de guerre à l'arsenal de Tienne, au milieu de drapeaux tricolores surmontés du, bonnet rouge. Bonaparte emporta avec lui des ballons en Égypte; ils furent perdus à Aboukil, et Conté en fit incontinent fabriquer de nouveaux. Si l'opinion de Jourdan fut telle en effet qu'il le dit dans ses mémoires, il est certain du moins que le Comité de salut public

(1) Voir les pièces concernant ces détails aux Archives nationales, AFIr, carton 67 . 
ne parlagea pas l'opinion du vainqueur de lileurus, car il double aussitôt le nombre des aérostiers et commande six ballons. Jourdan pouvait être un excellent général, mais nul ne contestera la compétence militaire du Comité de salut public, et son opinion vaut la peine qu'on s'y arrète. Bien d'autres traditions qu'il commença furent abandonnées. Avec l'élément civil, la science disparut peu à peu des armées; la guerre cessa d'ètre ce qu'elle était en l'an II : une école scientifique permanente. L'avenir nous réservait d'apprendre plus tard au prix d'une terrible expérience quels services l'emploi des ballons, combiné avec celui des pigeons, peut rendre, en permettant, malgré les blocus les plus rigoureux, un échange régulier d'ordres et de nouvelles entre une place investic et l'extérieur.

La création du télégraphe est antérieure à l'an II, et l'inauguration de la première ligne de Paris à Lille n'aura lieu qu'après thermidor: c'est pendant la Terreur qu'elle fut installée. Dès le 26 juillet 1793 , la Conrention avait nommé Claude Chappe " ingénieur télégraphe ), et s'en était remise à son Comilé de salut public du soin d'examiner quelles lignes il convenait d'établir tout d'abord. Les extraits qui ont été publiés de la correspondance de Chappe arec Lakanal montrent que ce n'est. pas sans difficulté qu'il était parrenu à réaliser ses premiers cssais. Les pièces que nous avons eues sous les yeux aux Archives font foi que plus tard, en l'an IV, les ennuis, les misères qui assaillent d'ordinaire les inventeurs ne furent pas épargnés au créateur du télégraphe. En 1793, le Comité des finances n'arait point d'argent pour tenter une expérience décisive; en l'an IV, e'est encorc l'argent qui manque pour payer les employés. Eh bien! les pièces nombreuses qui restent des rapports de Chappe avec le grand Comité de salut public en l'an II ne laissent rien voir de semblable. Le Comité favorise de tout son pouroir l'établissement de la ligne de Lille, qui se poursuit au inilieu de difficultés que l'on pent imaginer. Dès le 17 septembre, Chappe ne peut pas se procurer de fer, tout celui qui est à Paris ayant été mis en réquisition. Le Comité, par un arrêté signé Barère et Hérault de Séchelles, autorise Chappe a prendre dans les dépôts la quantité de tôle et de fil de fer dont il a besoin (1).

(1) Archives nationales, A Fı, carton 220. - Chappe avait aussi demandé dix-huit pendules (Reristre de la Commission des arts, 30 prairial et 23 messidor). i)ans le systeme de simaux imagiuć d’abord par Chappe, la mesurc rigoureuse du temps jouait un rôle important. C'est pour cela qu'il 
Le 24 septembre, le Comité fixe le chiffre de l'indemnité que touchera l'ingénieur télégraphe. En même temps, il requiert les municipalités de fournir à Chappe des ouvriers et des matériaux; au besoin on réquisitionnera (I). Le If́ prairial, nouvel arrèté décidant d'établir des postes sur Montmartre et sur le dòme du Lourre (2); les lunettes font défaut, on va se mettre à tailler des verres achromatiques. Enfin, arant même que la ligne de Lille soit achevée, le Comité de salut public, le 12 messidor, projette l'établissement d'une ligne de signaux de Paris à Brest, signaux qui devaient être faits au moyen de parillons par une suite de stations espacées de deux en deux lieues, mais beaucoup moins coûteuses et moins longues à installer que les machines télégraphiques.

Ce projet ne fut approuré qu'après le 9 thermidor. A cette date, la ligne de Lille, décidée six semaines arant Je commencement de la Terreur, était presque acherée. C'est le 13 fructidor qu'elle transmet à l'assemblée la nourelle de la reddition de Condé le matin même (3): la Conrention fait répoudre que ce nom doit ètre désormais changé en celui de Nord-Libre. La dépèche reçue le soir fut pour l'ennemi une surprise profonde; il s'imagina que la Conrention siégeait au milieu de l'armée française.

Le Comité de salut public prit une part non moins active à la réforme des poids et mesures. Un décret de 1790 arait confié le soin des études préliminaires à l'ancienne Académie des sciences. Celle-ci ayant été supprimée en aoủt 1793, les membres qui araient commencé le travail en restèrent chargés par décret du 11 septembre 1793, sous le nom de Commission temporaire des poids et mesures. Jamais réunion plus illustre de savants n’avait peut-être travaillé à plus grande œurre:

fit demonder i la Commission des arts des pendules de précision. Celle-ci hésita á se dessaisir dinstruments d'une aussi grande valeur pour les placer dans les postes télégraphiques entre Paris ct Lille. Chappe de son côté modifia son systéme de signaux et neut plus besoin de pendules. C'est certainement à cetle affaire que fait allusion le passage suivant du second rapporl de Grégoire sur le vandalisme: "Derniẻrement. pour un simple usage, on roulait que la Commission temporaire des arts accordat des pendules du plus grand prix ». On était alors en pleine réaction thermidorienne (3 brumaire au III). La passion entraine Grẻgoire jusquà reprocher à liancien Comité ce qüil arait cru devoir faire pour activer à lout prix l’établissement de la ligne télégraphique du Nord!

(1) Archives nationales, A Fil, carton 220.

(2) Ibid.

(3) [Arant la nourelle de la reddition de Condé, le télégraphe arait déjả ransmis a Paris celle de la repıise de deux autres places, le Quesnoy (2S thermidor) et Valenciennes ( 11 fructidor). - J. G.] 
nous y trouvons Monge, Borda, Lagrange, Laplace, Méchain, Delambre, Coulomb, l'abbé IIaüy, Brisson, Vandermonde, enfin Lavoisier; puis, un pen plus tard, Berthollet, remplaçant Tillet, mort en 1792. On n'attendait plus, au commencement de l'an II, que la mesure de l'arc du méridien entre Dunc-Libre (le nouveau nom de Dunkerque) et Barcelone, les astronomes français ayant été retenus prisonniers par les Espagnols avec qui nous étions en gnerre. La longueur du pendule qui bat la scconde arait été déterminée par Borda; Lavoisier avait pesé un volume d'eau déterminé. Les bases du noureau système métrique étaient solidement établies; il ne restait plus qu’à régler la forme des divers étalons, ì déterminer les méthodes pour les vérifier, et enfin à les faire exécuter; ce fut l'œurre de l'an II.

Lc $1^{\text {er }}$ du deuxième mois, la Convention, sur le rapport de Fourcroy au nom du Comité d'instruction, ordonne qu'il sera construit des étalons prototypes en platine, ccux-là mêmes qui sont encore conservés aux Archives dans l'Armoirc de fer et que la Commission internationale du mètre, tout récemment (1), a visités, admirant la perfection de la plus grande entreprise scientifique de la Révolution. En même temps, l'assemblée met 300,000 livres à la disposition du ministre de l'intérieur pour faire construire par d'habiles ouvriers les étalons destinés aux administrations. Le ministre, la Commission des poids et mesures, lc Comité d'instruction doivent s'entendre pour tout cela. Mais il semble, au moins d'après les documents que nous avons eus entre les mains, que d'abord rien ne marche. Le ministre était fort peu de chose; le Comité d'instruction n'avait pas lui-même grande autorité : le 6 frimaire Guylon s'enquiert au nom de celui-ci, près de la Commission, des obstacles survenus, sans paraitre avoir la puissance de les lever (2). En nivôsc Haïy, dans le local qu'il occupe près de son laboratoire, n'a pas même de lit (3).

C'est alors qu'intervient le Comité de salut public, et tout change. Et d'abord il épure la Commission (4); puis, le 18 plu-

(1) $[$ En 1873. - J. G. $]$

(2) Archives nationales, F 12, carton 1289.

(3) Ibid.

(4) Le 18 frimaire, la Commission a vait nommé Coulomb trésorier en remplacement de Lavoisier. L'arrêté du Comité de salut public qui l’épure est Hu 3 nivôse : Borda, Lavoisier, Laplace, Brissou, Delambre, Coulomb sont rayés; lagıange, Monge, Haüy, Vandermonde, Méchain et Berthollet sont maintenus, et IIassenfratz, Prony et Buache leur sont adjoints. La Commission ainsi épurẻe se présenta le 30 nivòse il la barre de la Convention. 
viôse, il requiert le ministre de faire imprimer unc Instruction qui devrait être déjà rédigée en exécution du décret rendu le $1^{\text {er }}$ août 1793. Il est probable qu'on l'arait oubliée (1). L'Instruction parut en germinal (2). La construction des étalons pour les départements était également en retard. Le 21 pluviôse, le Comité de salut public, considérant qu'il importe de favoriser par tous les moyens la fabrication des nouvelles mesures, accepte la proposition faite par un certain nombre d'ouvriers de se réunir à cet effet; il met à leur disposition une maison du cloître Notre-Dame; enfin il décide qu'on leur avancera - sous caution - une sommc de 25,000 lirres. Mais cette caution même devient une difficulté; les ouvriers ne la trouvent pas; c'est un noureau retard. Le Comité décide alors (4 rentôse) que les 25,000 livres seront avancées aux artistes, à charge par eux d'en justifier l'emploi (3). Deux mois plus tard, on apprend que l'astronome Méchain, chargé de la mesure du méridien sur la frontière espagnole, est prisonnier à Barcelone avec ses deux aides. Le Comité de salut public lui envoie 6,000 livres en numéraire. L'arrèté est signé Lindet, Prieur, Carnot, Robespierre, Barère, Collot d'Herbois, Billaud-Varenne (4).

La confection des nouvelles monnaies, ou, comme on les appclait alors, des " assignats métalliques», arait failli être un moment suspendue par l'arrestation de Lavoisier'. Ce nom, resté sur cette époque comme une tache que rien n'a pu laver, dit mieux que toutes choses quelle perte fit la France dans un sarant que la physiologie autant que la chimie regardent comme une de leurs gloires. La ferme avait été supprimée dès le 20 mars 1791 ; le 4 frimaire an II, Bourdon de $1^{\circ}$ Oise, le mème qui devait plus tard tant contribuer à renverser Robespierre, demande que les fermiers généraux, qui n'ont pas encore rendu leurs comptes, soient arrêtés et, s'ils ne les peuvent

(1) COn ne l'avait point oubliée, car dès le 17 nivôse le manuscrit de l'Instruction était prêt à être remis à l'Imprimerie nationale exécutive, et le Comité d'instruction publique demandait au ministre de l'intérieur de la faire tirer á six mille exemplaires. - J. G.]

(2) Le 12 germinal, I.agrange et Hariy, secritaires de la Commission des poids et mesures, adressent cette brochure au Comité de salut public.

(3) Archives nationales, Fi2, caiton 1289.

(4) "Le Comité, informé que Méchain, chargé de royager pour prendre la mesure exacte de l'arc, est détenu à Barcelone arec les citojens qui laccompaguent, lui fait parvenir 6,000 livres en numéraire. Le présent arrêté sera enroyé à la Commission de l'instruction publique et aux commissaires de la trésorerie. Pour extrait: Caruol, Lindet, Collot, BillaudVarenne." (Archives nationales, F12, carton 1258.) 
rendre, "livés au glaive de la loi ». Vingt-huit fermiers généraux sur soixante furent retenus, et Lavoisier dunombre, comme ayant tiré des bénéfices illicites de baux conclus par eux aree les nommés David, Salzard et Mager, probablement trois juifs. Le mois suivant (23 niróse), la Convention, sur le rapport de Dupin, parlant an nom de la Commission chargée de reviser les comptes des trois compagnies de finances, décrite que les biens des fermiers généraux sont sous la main de la nation.

L'enquête sur la ferme générale fut longue, très longue en un temps où on menait révolutionnairement toutes choses. C'est le 16 floréal seulement que Dupin présenta, au nom de la Commission el des trois Comités de súreté générale, des finances, et de l'examen des comptes, un long rapport plcin de chiffres et purement d'affaires. Lavoisier n'est pas nommé, non plus que ses collègues. Les griefs articulés contre eux sont nombreux et graves, s'ils reposent sur des allégrations viaies. Le moindre est d'aroir falsifié le tabac en le surchargeant d'eau au point qu'elle coulait des barriques. Lavoisier, dals son interrogatoire, n'a pas nié ces fraudes; il a dit seulement qu'il les avait signalées lui-même au ministre cliaque fois qu’il en avail été informé (1). Mais il s'en faut que ce fùt là le seul ou le principal considérant du rapport de Dupin. La Convention renvoya séance tenante les vingt-huit fermiers généraux au tribunal révolutionnaire. Nul dans l'assemblèe ne pouvait se faire illusion sur le sort qui attendait des hommes flétris par elle, devant ce jury redoutable qui ne pouvait choisir qu'entre l'acquittement et la peine capitale (2).

On est presque épouvanté de l'abandon gxénéral au milieu duquel tomba cette belle tète. On raconte, nous ne savons d'après quelle source, que Hallé, au nom du Lycée des arts, porta au prisonnier une couronme qui semblait presque un hommage funèbre. Cette histoire est probablement apocryphe (3).

(1) "Interrogé s'il ne s'est pas rendu coupable de dilapidation des finances du gourernement, dexactions, de concussions, et de fraudes envers le peuple? - Répond que, quand il a connu quelques abus, il les a annonces au ministre des finances, untamment relativenent au tabac, ce qu'il est en etat de prouver par pieces authentiques. " - Interrogitoire du 18 floréal an II.

(2) [Cette dernidre affirmation est un anachronisme. La disposition portant que "la peine portée contre tous les délits dont la connaissance appartient au tribunal révolutionnaire est la mort "n'existait pas encore; elle n’apparaitra qu'avec la loj dı 22 prairial. - J. G.]

(3) [EIle est attestée par le témoignage de Charles Desaudray, administrateur du Lycée des arts (dans une note publice en l'an W), et par un 
Après l'arreslation de Lavoisier, seul le Comité des assignats et monnaies adressa une énergique protestation an Comité de salut public (1 er niròse). "La pièce de 5 décimes est prète, dit-il; les flaons sont découpés; sous quatre ou cinq jours on peut en avoir fabriqué pour 50,000 livres »; mais il faut des poids pour peser ces pićces, des poids nouveaux dont la fabrication est d'une extrème délicatesse, et la fabrication de ces poids vient précisément d'ètre suspendue par l'ar'estation de Lavoisier. "Prenez telle mesure que rous eroirez convenable à l'égard de ce citoyen, mais il fant qu'il puisse travailler dans son laboratoire... S'il n'y a pas de faits graves sur son compte, faites en sorte que l'actirité soit promptement rendue aux travaux dont il est chargé, arec toutes les mesures de súreté que vous croirez d'ailleurs convenables (1). 》

L’intérêt naturel qu'inspira an début le sort de Laroisier à ses amis, à ses collègnes, ne pourait durer. On doit toujours, quand on veut se rendre compte des actions des hommes à une époque déterminée de l'histoire, envisager ce qu'on peut appeler l'état psychologique à ce moment. On a beaucoup parlé de celui de Paris après le siège: il parut extraordinaire, parce qu'il n'était pas à l'unisson do reste de la France séparéc pendant quatre mois et demi de la capitale. En l'an II l'état mental de la nation tout entière était certainement monté à un diapason que nous ne saurions comprendre et que nous arons le tort de juger trop absolument arec nos sens rassis. Le régime de la Terreur ne fut point le fait d'un groupe de sinistres bandils qui tinrent la France sous leurs pieds comme une proie; la Convention personnifia bien ceriainement le génie de la nation tout entière a cette époque, depuis les sarants jusquau dernier paysan. Ce serait attribuer aux hommes de science de ce temps-là de bien làches complaisances que de croire qu'ils se turent seulement par crainte, et qu'ils servirent la Rérolution par effroi. La procédure contre les vingt-huit fermiers généraux

passage d'un rappori de Lakanal du f reudémiaire an IV. Voir Lavoisier. par E. Ghisuzx, p. :95, note. - J. G.]

(1) Archives natiouales, Alik, carton 2200. - [Le Comitś des assignats et inonnaies ne fut $p$ is : eul i interrenil eu fareur de Laroisier. Deux jours arant, le 28 frimaire, la Commission des poids el mesures arait écrit au Comité de sùreté générale pour lui reprisenter " combien il était ưgent que ce citogen pùt itre rendu anx travanx importants qu'il a toujours suivis arec autant de zile que d'activite ". Sur celte demande le Comite de sủreté générile passa à lordre du jour, motiré sur ce que " le citoren Lavoisier est porłé sur la liste rles ci-derant fermiers généraux mis en étal d'arrestation en exécution du decret de la Conrention nationale ». - J.G.] 
avait été lente (1); deux Comités, une Commission spéciale avaient examiné les comptes; le rapport de Dupin élait catégorique; la Convention avait prononcé. Comment les contemporains n'eussent-ils pas cru à l'équité soureraine de ses jugrements?

Le 19 floréal (2), l’allaire fut appoléc au tribunal révolutionnaire. Les juges étaient ce jour-là Coffinhal, président, Foucault et Denizot, assesseurs. On interrogea les prévenus, on fit ensuite lecture de l'acte d'accusation. Les débats, si on peut leur domner ce nom, furent terminés le jour mème et le jugement rendu. Il ressemble ì tous ceux du tribmnal : la sentence frappe l'éternelle conspiration ayant pour but de faroriser par des menées le suceès des ennemis qui menacent la République au dedans et au dehors.

Il y avait eu un incident à l'audience. Le président reçut au cours des débats un décret de la Convention. Toici ce qui s'était passé: Dupin était monté à la tribune pour notifier que trois adjoints aux fermiers généraux, impliqués dans le même renvoi au tribunal, avaient élabli la preure qu'ils n’avaient pu participer aux bénéfiees illieites des baux David, Salzard et Mager. Le rapporteur demandait en conséquence que ces adjoints fussent mis hors des débats. La proposition est adoptée, et le président dépêche aussitôt un huissier de service au tribunal pour lui transmettre le décret, qui arrive à temps (3).

Ce président était Carnot, plus à mème peut-être que tont autre dans l'assemblée d'apprécier quels services aurait pu rendre Lavoisier. Il se tut cependant, et ceux-là seuls songeront

(1) On s'élonne de relrourer dans l'Histoive de l'anciemne Académie, par M. Berlrand, quelques lignes sur le procis de Lavoisier, empreintes de la lègèreté singulière avec laquelle la plupart des biographes ont traité ce triste sujet. M. Bertrand semble croire que quelques instants ont leceidé du sort de Lavoisier, quand en réalilé le procés a duré plusieurs mois, non devant le tribunal révolutionnaire, mais devant la Convention.

(2) Le 10 lloréal, Lavoisicr avait certifié dans sa prison un mémoire de travaux exécutés pour les poids et mesures, cn aoìt et septembre 1793, par un nomme linandy. (Arehives nationales, J12, carlon 1288.)

(3) " I)u 19 flopial. La Convention, après avir entendu le rapport des Comités de suretégénérale, funances et examen des comptes réunis à la Commission, déclare que les aljoints des ei-devint lermicrs généraux qui seront en elat de justifier, par un cerlificat signi des citryens reviseurs, qu'ils n'ont en aucune espece d’intérêt dans les baux de liavil, Salzard et Mager, n'ont pas été compris daus la loj du 16 llor'al, qui renvoie les ci-devant fermiers généraux an tribunal révolutionnaire; décréte en conséquence que les citoyens De la llante, Bellefaye el Sanlot seront mis a linstant bors des dẻbats. v 
à lui en faire un reproche qui croiront qu'à cette époque, à ce moment, la conscience de ces hommes se décidait par les mêmes motifs que les nòtres. La vérité est que Lavoisier pour tout le monde alors fut coupable et mérita la mort. Le Comité de salut public, qui savait si bien apprécier le rôle des sciences, ne chercha point à saurer cette victime de l'échafaud; seul peut-être il en arait la puissance. A ce moment même il cherche des chimistes. Le 11 floréal il fait Joger dans la maison du cidevant duc de Liancourt le citoyen Rourier, chimiste, en toute bâte (1). Le 28, une décision du Comité de salut public institue à Meudon un atelier pour" "la fabrication de muriate suroxygéné de potasse (2) ). C'est peut-être le premier document officiel où figure le nom de l'oxygène découvert par Lavoisier ; il n'y avait point encor'e une décade que celui-ci était monté sur l'échafaud.

Au Comité d'instruction, où siègent Fourcroy et Guyton qui n'est point encore parti pour l'armée du Nord, on ne s'inquiète pas de Lavoisier. A la Commission des arts on en parle si peu que l'agent chargé de rédiger les procès-verbaux ne sait pas même l'orthographe de ce nom illustre, quand il l'écrit pour la première fois au moment de faire l'inventaire des objets de science et des instruments ayant appartenu au ci-devant fermier général.

On a prétendu que Lavoisier avait imploré un sursis pour terminer certaines cxpériences. L’homme qui avait négligé de prendre un défenseur n'a pas dù descendre à la prière. Quant ì cette réponse prêtée plus tard par Fourcroy au président du tribunal, «que la République n avait plus besoin de savants et qu'un seul homme d'esprit suffisait à la tète des affaires », une telle phrase n'appartient pas certainement au langage de floréal, où Robespierre n'était pas encore le " tyran » qu'on renversera le 9 thermidor, et où la pensée ne serait venue à personne, pas mème aux fidèles de Robespierre, de supposer UN homme à la tête des affaires.

On a dit aussi que $M^{\text {me }}$ Laroisier, par une démarche auprès d'un employé du tribunal, eût pu sauver la tête de son mari : c'est ì la fois méconnaître étrangement le rôle et l'esprit du tribunal; c'est surtont se tromper sur les événements ou les ignorer. La véritable sentence de mort de Lavoisier fut le vote de la Convention.

Après thermidor, Dupin va payer de sa liberté le rapport qui

(1) Arrêté du Comité de salut public en date du 11 floréal (A Fin, carton 220).

(2) A Fil, carton 220 
arait fait condamner les vingt-huit fermiers généraux (1) : l'esprit public s'est encore relourné, mais il n'est guère plus calme; apres la fureur révolntionnaire, les représailles thermidoriennes! En boune psychologie, les jugements de l'an $11 \mathrm{l}$ valent exactement cenx de l'an II : les fermiers généraux ne sont plus coupables de bénéfices illicites; c'est la nation qui est en retour avec eux. La rérité est que ce procés financier n'est point encore jugé, qu'il faudrait le reprendre par les chiffres sur les documents qui doivent encore exister, et refaire l'histoire certainement intércssante des baux Darid, Salzard et Mager.

\section{VI}

Nous arons montré le Comité de salut public mêlé aux grandes entreprises scientifiques décrétées avant le régime de la Terreur, ou dont Jui-même eut l'initiative; son action sur les établissements scientifiques qui datent de la Rérolution n’est pas moins décisive, soit qu'il travaille à l'agrandissement de ceux qui existent déjà, soil qu'il en fonde de nouveaux inaugurés seulement après le 9 thermidor.

Il existait à Mézières une Ecole ci-derant royale de génie militaire. A la suite d'un rapport sur les traraux publics présenté le 21 rentùse an II par Barère, le Comité de salut public décida que cette école serait transférée à Hietz, où elle prendrait un caractère exelusirement pratiı̨ue, comme Ecole de siège. Mais en même temps le Comité ordonne que le matériel d'instruction, les livres, les plans en relief, les modèles de coupe de pierres, les instruments de physique seront iransportés à Paris, " pour servir à un centre de rémion de toutes les branches de l'instruction relative aux travaux publics " : e'est le germe de l'Ecole polytechnique, qui n'aura pas tout d'abord ce

(1) [Le 16 floréal an III, jour annïersaire du dépôt de sỏn rapport sur les fermiers généraux, Dupin fit spontanément amende honorable à liz tribune de la Convenlion, déclara qu'il n'avait écrit et déposé son rapjort que pour sauver sa lâte et sous Je coup des menaces d'un membre du Comite de salut public, et demanda que la confiscation prononcée contre les fermiers géńraux fùt de nul effet (celle demande était supernlue. la Convention ayant déjii roté l'avant-veille, f́t llorial, un décret généril porlant yue les bieus des condamués depuis l'éjoque du 10 mars 1793 seraient rendus a leurs familles!. Nédnmoins, trois mois plus tarl, le 22 the l'midor an 11J, sur Ia déuoncialion de Lesage d'Eure-et-Loir, Dupin fut décréte d'arrestation. Compris dans l'amnistie du \& brumaire an $\mathbf{N}$, il est mort a Iarcinelle pris Fleurus (Belgique), en 1833. - J. G.] 
nom. Six semaines après le 9 thermidor, Fourcroy, porté à son tour au Comité de salut public, vient annoncer à la tribune de la Convention que l'Ecole centrale des travaux publics est prête à receroir les élèves. Fourcroy ne se déclare pas encore, comme il fera plus tard, " contre cette tyrannie qui roulait courrir la France de deuils et de tombeaux »; Fourcroy au contraire loue ses prédécesseurs au Comité de salut public de n’aroir cessé - dit-il - de préparer tous les moyens nécessaires pour lorganisation de ce nouveau foyer d'enseignement (1).

(I) Le noureau Comité de salut public demande a la Commission des arts, à la date du 16 fructiclor, un certain nombre d'objets pour l'Ecole centrale des travaux publics, "conformément aux bases arrêtées par le Comité en conséquence de la loi dı 2 I ventôse ". (Registre de la Commission des arts, 20 fructidor).

Daus son Histoire de l'Erole polytechnique, écrite en 1823 et dédiée au Dauphin, II. Fourcy attribue à tort un rôle important dans la créalion de l'Ecole à la Comuission des arls, qu'il aupelle une espece de congrès de sarants, et dont il unéconnait entièrement le caraclère. Il se trompe aussi quand il attribue à IIonge une grande influence daus cette Comarission, aux travaux de laquelle le célèbre géomètre ne prend ì cette époque que fort pen de part, absorbé qu'il était par les travaux de la défense. Le seul rûle de la Commission les arts fut de pourroir aux besoins de la nouvelle Ecole, en fournissant. le compléwent du matériel apporté de IIézièrez et en particulier le cabinet de phrsique. M. Four cy remarque qu'une partie de ces instruments apparlenaient an garde-ureuble de la couronne, quelqquesuns à l'Académie des sciences, d'autres à des particuliers. Et il ajoute avec mélnncolie: "Le sentiment pénible excité par de tels sourenirs est à peine adouci par la pensée qu'en cette occasion ce fut la science, la patrie, et noul la cupidité qui profitı $d$; ces tristes dépouilles".

[Pouchet donne dans cette note une interprétation elronée à une page du livre de II. Fourcy. Voici ce qu'a écrit l'auteur de l'Hisloire de l'Ecole polytechnique (p. 13): "Il y avait alors, auprès du Comité de salut public, une espéce de congrès de savants, ou la plupart des sciences exactes et natırelles se truuraient dignement représentées. C'est de lá que partaient, à la roix du Comité souverain, ces instructions luminenses, ces inventions soudaines, ces expédients ingénieux et rapides qui, dégageant lẹs procédés des arts des vieilles ornières de la routine, élevaient tont à coup leurs produits au nireau des immenses besoins de la Rérolution. Dans cette réuuion, que son éminente utilité recommandait si puissamment à la bienveillance du gouvernement, Monge se distinguait par cette infatigable activité qu'il porlait d'ordinaire sur tout objet qui arait saisi fortement son imagination; et il s'était ainsi concilié la prédilection particulière des chefs de la képnblique. ". II. Fourcy n'a nullement voulu parler ici de la Commission des arts : ce qu'il appelle "une espèce de congrẻs de sarants", ce sont ces chimistes, ces physiciens, ces mathématiciens que le Conité de salut public arait appelés à lui pour nliliser leur génie en rue de la défense nationale, et au premier rang desquels figuraient Guyton, Fourcroy, Monge, Hassenfratz, Vandermonde, Lagrante. Berthollet, Leblanc, etc. Dans un autre passage, du reste (j. 16), 11 . Fourcy mentionne expressèment " la Commission temporaire des arts, établie jrès le Comité d'in- 
Nous ne dirons qu'un mot de l'Ecole de Mars, décrétée le 13 prairial au milieu des applaudissements de la Convention, sur un rapport de Barère au nom du Comité de salut public (1). Les élèves, affublés d'un costume ì l'antique qu'arait dessiné David, y recevaient révolutionnairement l'éducation militaire avant d'être envoyés aux armées. Le Comilé avait également institué des cours révolutionnaires pour la fabrication du salpêtre, auxquels chaque département dut envoyer un certain nombre d'élères (2).

L'Ecole des mines fixe aussi l'attention du Comité de salut public. Il décide qu'elle aura, indépendamment de la salle des conférences et des licux destinés aux cours publics, une biblinthèque lilhologique de minéralogie, de docimasie et de métallurgie; un cabinct de modèles de fourneaux et de machines scrvant à l'exploitation des mines; un cabinet de cartes et de dessins; un dépôt de manuscrits relatifs à l'histoire des pierres; un cabinct de minéralogie contenant toules les productions du globe et tontes les productions du sol de la République rangées suivant l'ordre de la localité; cnfin un laboratoire pour les essais. On ne saurait tracer d'une main plus ferme, et plus complètement, le plan d'une institution scientificue (3).

Partout c'est la même sûreté de jugement qui crée pour l'avenir, comme s'il suffisait de vouloir. A côté de l'Ecole polytechnique et de l'Ecole des mines, voilà le Conservatoire de musique qui s'élève. Le 18 brumaire, les musiciens de la garde nationale de Paris, ayant à leur tête une députation de la com-

struction publique n, et ce qu’il en dit nuntre qu'il ne l'a pas confondue avec le "congrés de savants " dont les travaux - comme Pouchet l'a fort bien remarqué - absorbaient presque toute l'activité de Monge. - J. G.]

(1) Barère, dans ses Mémoires, attribue à Carnot l'idée de l'Ecole de Mars.

(2) [Ces cours, divisés en trois séries, durèrent du 1 er ventôse au 20 geruinal. - . . . . .

(3) Lrt. 19 de l'arrêté du Comité de salut public du 18 messidor an II. (Voil le renistre de la Commission des arts, 30 messilor.) Sage, ancien membre de l'Académie des sciences, professeur et lirecleur de l'Ecole des mines, avait été arrité dans le milieu de brumire. La Commission des arts invita le Comité d’instruction publique à "réreiller l'attention de la Convention nationale sur l'étude de la uinéralogie el sur la nécessilé d'encourager les hommes qui professent les principes d'un art si utile à la chose publique " (kegistre, 23 brumaire). Le 30 frimaire, Sage fait demander d’aller faire son rours de minéralogie et de docimasie à la Monnaic avec un garde. La Commission des arts appuie, ef invite de nouveau le Comité d'instruction publicue à intervenir soit auprès de la Convention, soit auprès du Conuité de sûreté générale. 
mune, viennent à la barre de la Convention réclamer l'établissement diun Institut national de musique. Sur la demande de Chénier, le Comité d'instruction est chargé des moyens d'exécution, mais il ne se hàte guère, et ici encore nous royons intervenir le Comité de salut public (1). Le 10 floréal, il autorise les professeurs à choisir les meilleurs instruments parmi ceux qui sont aux mains de la nation ( 2 ); le 28 floréal, il affecte à l'Institut national de musique les bâtiments qu'il occupe encore dans la rue Bergère: l'arrêté est signé Barère, Billaud-Yarenne, Carnot et Prieur.

Nous trourons encore le Comité de salut public associé pendant cette période à l'histoire des Gobelins, où il fait installer la salle dexposition (3). Tous le royons aussi, en messidor, réglant, de concert arec le Comité d“instruction, un concours assez bizarre. Il s'agit de trourer un artiste pour restaurer les toiles du Musée national (4). On décide de prendre un des tableaux les plus endommagés, qui se trouva être un Rubens, de le partager en plusieurs morceaux et de donner ceux-ci aux concurrents pour y montrer leur talent. C'est à cette mesure, conseillée probablement par David (j), que fait allusion Courtois

(1) [Cette assertion est inexacte; Pouchet a ignoré la part qui revient au Comité d'instruction publique dans les uesures prises en faveur des musiciens. Dès le II nirôse, le Comité approure le plan, présentẻ par Sarrette, d'une publication unsicale mensuelle, et charge Gurtou de se concerter avec le Comité de salut public pour les moyens d'exécution: le 29 rentôse, il propose qu'une subrention meusuelle de 1,200 lirres soit accordée aux musiciens, en supplément des fonds que leur alloue la coumune de Paris. Le Comité de salut public ne fait quapprourer : le 27 pluviòse, il lonne 33,000 livres pour le recueil de musique à l'usage des fítes n itionales; le 4 floréal, il accorde la subrention mensuelle de 1.200 livres. - J. G.]

(2) Liarrêté du Comité de salut public autorisait les professeurs de l'Institut à se transporter arec les commissaires du département dans les maisons d'émigrés et de condamués pour faire leur choix. La Commission des arts fit observer qu'elle-meme dressera linventaire de ces instruments, c'est près d'elle qu'on les trouvera. (Registre, 10 floréal.)

(3) Par un arrété du 30 messidor, le Comité de salut public arait indiqué le mode de nomination du jury qui devia decider quels tableanx seront reproduits en tapisseries. Cet arrèté est visé dans un autre du mème Comité, en date du 3 fructidor an II, qui nomme ce jury.

(4) L'idée de ce concour's appartiendrait à la coumune, d'après Michelet (Histoire de la fiévolution, t. VI, p. 361, 13 frimaire, - [Michelet a raison: voir le Moniteur du 1 ŏ frimaire an II. - J. G.]

(5) [Le rapport sur la restauratiou des tableaux, statıes, bas-reliefs, etc., formant la collection du ILu-éum national, avait été présenté á la Convention, au nom du Comité d'instruction publique, par Bouquier, le 6 messidor. Bouquier était un amateur éclairé, qui avait fait lui-méme de la peinture. - J. G.] 
dans son rapport sur les événements de thermidor, quand il dit sottement que Darid roulait « qu'on divisat par échantillons les superbes tableaux de la galerie de liubens, qu'on aurait ensuite distribués à des élères pour des essais de nettoyage ". Le texte même de l'arrêté (1) qui règle le concours fait justice de cette grossière ineptie, inspirée pas la haine contre les menbres de l'ancien Comité et leur's amis. Rappelons encore que les acteurs Dumesnil (2) et Préville virent leur vieillesse garantic du besoin par les soins de ce Comité de Vandales.

De quelque coté qu'on tourne les yeux, c'est la méme activité, Pendant qu'il crée l'Ecole polytechnique et le Conservatoire, pendant qu'il agrandit l'Ecole des mines et le Muséum, le Comité de salut public songe aux embellissements du jardin national des 'Tuileries. Que n'a-t-on pas dit des plantations de pommes de terre dans les jardins royaux, ou l'on n'a ru qu'une révolte barbare contre le passé, à mettre sur la même ligne que ces semailles de sel ordonnées par Louis IIT sur l'emplacement de Port-Royal! La commune, d'oú l'idée vint d'abord, était peut-être capable de telles défaillances intellectuelles. Mais du moins ce ne ne fut pas ce jour-là. La séance du 21 pluviôse arait été remplie à la commune par des réclamations affamées. La viande allait laire défaut, on dénonçait les bouchers. Alors, par un travers propre aux corps délibérants, on cherche le remède à un mal présent dans des mesures à long terme. Pour combattre la famine qui menace, le Conseil général ne troure rien de ınieux que d'inviter, dans cette séance même, le département a faire mettre en culture les terres des jardins de laxe (fort nombreux alors) qui sont dans la tommune de Paris. Il est très certain que, pour la plupart, les membres du Conseil étaient fort insensibles à l'art des jardins, et que les chefs-d'œuvre de Le Nôtre ne valaient pas à leurs yeux un bon champ de froment, étant en cela de l'avis'des paysans de la Beauce ou du pays de Caux.

(1) Du 7 messidor. Arrèté du Comilé de salut pullic réglant les mesures Ju concours, en exécution du décret du 6 messidor. Sigené an registre : Barère, Billaud-Varenne, Robespierre, Collot d'Herbois, Prieur, Couthon, Can not, Lindet. Pour extrait : Billaud-Yarenne, Carnot, Robespierre. (Fi', cartou 1306.) Limputation dirigée ici contre Davil est encore plus absurde quand on se reporte á son rapport dı 27 nirôse, où il se plaint des restaurations maladroites: "La Vierge du Guide n’a point été nettoyée, mais usée. Le Joïse foulant aux pieds la couronne de Pharaon, de Poussin, n'est plus qu'une toile abimée de rouge et de noir, perdue de reslauratiou. "

(2) Lactrice Dumesnil recut en l'an VII une pension du gouveruement (Voir Moniteur, an VII, ii); ce n'est point d'elle qu'il est ici question. 
Le Comité de salut public, qui va présenter dans quelques jours à la Convention les tableaux du maximum, s'empare de l'idée de la commune aussitòt transformée. Le $1^{\text {er }}$ ventôse, il charge le ministre de l'intérieur de donner des ordres pour faire planter des pommes de terre dans un cerlain nombre de carrés des Tuileries et du Luxembourg (1). Ce fut Thouin, professeur de culture au Muséum, qui fut désigné pour l'exécution. Les pommes de terre étaient rares à ce moment; celles qu'on apportait à la halle de Paris étaient aussitôt enlevées; on les payait cent sols et six livres le boisseau (2). Pour s'en procurer sans dégarnir le marché, au risque de provoquer des clameurs, Thouin dut faire chercher dans les campagnes environnantes ses pommes de terre pour planter (3). Dès le 20 ventóse, le Comité de salut public s'informe du point où en est l'exécution de son arrêté. On planta aux Tuileries les pommes de terre le long de la terrasse des Feuillants, probablement entre elle et les arbres, en ayant soin de protéger cel espace par des treillages. On ehoisit également un certain nombre de carrés au Luxembourg.

Le ministre, en transmettant ses instructions à Thouin, interprète la mesure du Comité comme prise à l'eflet de convertir ces terrains, dont le luxe a privé le peuple, en terres nourricières. Ce sont bien là les idées de la Commune. Mais on peut supposer que le Comité de salut public, tout en paraissant se conformer aux vues étroitement utilitaires de l'Hôtel de Ville, poursuivait un but plus général, plus élevé, car il autorise seulement la mise en culture de "quelques carrés ». Une lettre de Thouin nous apprend qu'on avait disposé de mêmo des plants de haricots et de légumes au Muséum, dans les jardins de la mairie, du Trésor public, de la Commission des subsistances; et que devant les plates-bandes on arait mis des éliquettes avec les noms des végétaux, afin que les yeux des visiteurs venus des

(1) "Le Comité de salut public arróte que le ministre de l'intérienr donnera les ordres nécessaires pour faire planter des pommes de terre dans les carrés du jardin national des Tuileries et dans les carrés du jardin du Luxembourg. Signé au registre: Barëre, Carnot, C.-A. Prieur, Saint-Just, Collot d'Herbois, Couthun, Robespierre, Lindet. Pour extrait : Barère, Collot, Carnot." (F17, carton 122.2.)

(2) Lettre de Paré, ministre de l'intérieur, à Thouin, en date du 17 ventôse $\left(\mathrm{F}^{17}\right.$, carton 1222).

(3) Dans la lettre citée (note précédente), Paré dit qu' "il a représenté au Comité de salut public qu'il fallait acheter les pommes de terre pour planter, à la campagne et non à la halle, oủ ce fruit (sic) est aussitôt enlevé par le peuple 
départements en fussent frappés et "que l'instruction les suivr dans tous les lieux publics qu'ils fréquentent (1) \%.

Ce zèle qui éclate partout, à celte époque, pour l'instruclion populaire, avec plus ou moins de bonheur, n'arait-il pas imaginé une nomenclature toute géographique des rues de Paris ( 2 et l'enseignement de l'histoire par des inscriptions aux barrières de la cité (3), de manière que l'instruclion nationale "sorte des pierres mèmes entassées par la tyrannic n!

Au reste, le Comité de salut public était si éloigné de rouloil. transformer en cliamps de pommes de terre les anciens jardins royaux qu'il s'oceupe de l'embellissement de celui des Tuilcries. Dès le commencement de floréal (4), il appelle Thouin pour s'entendre arec lui à ce sujet. Il approure le plan de Hubert (25 floréal) : il décide qu'on emploiera, pour orner le jarlin de la nation, les orangers qui se trouraient dans les chàteaux des environs de Meudon et de Saint-Cloud; la terrasse des Feuillants et celle du bord de l'eau recerront des statues et des vases, cí

(1) Lettre de Thouin en date du 23 rentôse ( $\mathrm{F}^{3 i}$, carton 12292).

(2) Voir lapport au Conseil général de la commune de Paris, imprimé en vertu de l'arrêté du Comité d'instruction publique du 17 nirôse. II y' eut aussi un systeme de dénomination des rues par Grégoire, imprimé par ordre du Comité d'instruction. - L'intérêt qu'excite à cette époque !a géographie mériterait certainement une étude spéciale, surtout depuis que nous avons appris cruellement combien, de ce còté, nous étions en retard. Le 20 messidor, la Commission des arts s'entretient d'un projet de jardin de géographie pratique qui pourrait lui être soumis de concert par les professeurs du IIusẻum et le Comitẻ dinstruction. Le 30 messidor, la Commission décide décrire au Comité de salut public au sujet d'un arrité sur les cartes et plans de géographie, pour montrer qu"il y a inconvénient á les accmuler dans un seul endroit, et arantage, au contraire, á les disséminer (Registre). - On ne doit pas oublier que Dumez, municipal, guillotiné le 11 thermidor, était l'auteur de l'Allas national de France.

(3) liapport fait a la Convention au nom du Comité de salut public par Barere, sur Ypres, 13 messidor : "Les portes de Paris derront raconter les faits d'armes des patriotes. Les triomphes de l'ar'mée d'Italie poucront bien être substitués sans regret au nom de la Porte de l'Etoile! Les artistes et les gens de lettres sont inritẻs a ce concours. "Li décret ordonne que les bâtiments désignés sous le nom de harriéres de Paris seront érigés en unonuments publics. Enfin le Comité de salut public, par un arrété du 16 messidor, décide que des inscriptions y relateront les journées de la Rérolution.

(4) "La Commission autorise le citoyen Thouin á se retirer auprès du Comité de salut public pour prendre conmunication de ses projets relativement aux embellissements du jardin national des Tuileries, et à l'emploi, pour cet usage, des orangers qui se trourent dans les maisons nationales de Saint-Cloud, de Sceaux, du Raincr, de Bellerue, de Ilcudon, etc., afin de faire choix de ceux de ces arbres qui pement le mieux servir i remplir les rues du Comité de salut public. "(Registre, 10 floréal.) 
le Comité autorise l'enlèvement, de la maison d'Orsay, de trente bustes en marbre pour servir à cette décoration(1); il y aura, dans le jardin, des exèdres tels quion les y roit actucllement, "semblables à ceux où les philosophes grecs donnaient leurs instructions ») et les chevaux de Marly seront placés à l'entrée des Champs-Elysées, où, en effet, ils furent plus tard apportés; David, Fourcroy et Granet étaient chargés de surveiller lexécution de cet arrêté. Le 9 thermidor ne permit point aux hommes qui avaient roulu toutes ces choses d'en voir l'accomplissement.

G'est encore à l'époque de la Terreur qu'apparticnt une idée qui ra ètre appliquée pendant les guerres du Directoire, et dcvenir, lor's de la campagne d'Égypte, la source d'une gloire scicntifique nouvelle pour la France. Jamais les monarchies n’avaient songé à utiliser la guerre pour faire tourner officiellement les campagnes des généraux au profit des sciences ct de l'instruction nationale. Celte vuc toute nouvelle appartient en propre ì la première Républiquc. Elle n'avait déja plus cours sous l'Empire, dont les maréchaux n'ont point cnrichi - directement du moins - nos collections nationales. Et lors de la dernière guerre, pendant qu'à l'approche des Allemands nous cachions avec soin nos richesses artistiques ou scientifiques, cenx-ci ne songeaient pas, il scmble, à les enlever; alors que tant de fourgons roulaient vers l'Allemagne chargés de dépouilles particulières, les musées publics ont été partout scrupuleusement respectés.

Mais pendant la Révolution, la France ne faisait point à l'Europe une guerre comme une autre. La France n'était plus sur le mème pied que les "nations esclaves». Le peuple affranchi avait tous les droits (2); il se croyait maitre de la terre cntière, parce qu'il se sentait capable de la conquérir ; la coalition était vaincue; la flotle républicaine elle-même ne venait-elle pas de balancer la fortune de l'Angleterre? L'empire des continents et des mers allait passer aux mains du peuple souverain : il pourra

(1) "Le citoyen IIubert (l'architecte) prévient la Commission qu'il a chargé, d'aprés un arrèté du Conité de salut public, les ciloyens Cauchi el Hersent, marbriers, de faire enlever de la maison d'Orsay treule bustes antiques, ctc. D (Registre, 1 m mairial.)

(2) Dans un rapport présenté le 21 ventôse an II sur les relations de la République française avec les nations alliées on neutres, Barére disail : "La Convention nationale doit se regarder comme chargée du bonheur du monde et de l'alliance générale entre tous les peuples. - J. (8.] 
du moins assouvir cette soif d'instruction et de connaissances qui dévore la nation entière!

Dès pluviose, un membre de la Commission des arts, Besson (1), avait déjì, à propos du Palatinat, émis cette idée légitime de lever comme tribut sur les nations vaincues les objets de tonte nature pouvant servir à l'accroissement des connaissances et ì la diffusion des lumières. Le 20 messidor, au moment où la bataille de Fleurus oure les Pays-Bas, il renouvelle sa proposition; mais on lui répond que déja le Comité de salut public a décidé d'envoyer ì l'armée du Nord une société de savants chargés de faire la recherche et la collection des cliefsd'œuvre des Pays-Bas. Le procès-verbal de la sćance où sont consignés ces détails laisse penser que ce fut sur l'invitation de la Commission des arts que le Comité adjoignit, aux commissaires déjà envoyés, des hommes de science. Nous royons, en effet, le \& thermidor, les professeurs du Muséum. sur l’invitation du Comité de salut public, désigner Faujas et Thouin. La journée du 9 thermidor, qui survient presqu'aussitôt, ne nous permet pas de les suirre. Ce serait une intéressante histoire que celle des sciences aux armées de la République, mais qui n'appartient point à l'époque oủ nous nous renfermons. Elle commence après thermidor pour finir avec l'Institut d'Egypte; mais le mérite d'avoir institué la première commission savante aux armées appartient au grand Comité de salut public.

Le Muséum d'histoire naturelle n'allait plus suffire à receroir tant de richesses attendues. Il faudra l'agrandir. Le décret du 10 juin 1793 avait réglé l'organisation définitive de l'ancien Jardin du roi, en lui donnant le nom qu'il porte encore. Le 11 septembre la Convention avait, sur le rapport de Fourcroy, affecté une somme annuelle de 6,000 livres à la continuation de la magnifique série de vélins déjà commencée (2). Redouté se met à l'œuvre, et le pinceau du peintre des roses, pendant la suprême convulsion de l'an II, ne s'arrête pas plus que celui de David.

D'autres décrets avaient ordonné de transporter au Muséum les arbres et les plantes rares provenant des domaines des émigrés. Le 19 pluviôse, le Comité de salut public, que nous retrouvons encore ici, s'enquiert à Daubenton, directcur temporaire du Muséum, si l'on s'occupe en effet du transport de ces nou-

(1) 11 y avait aussi un Besson conventionnel. Celui dont il s'agit ici était nembre de la Commission des arts, section de l'histoire naturelle.

(2) Voir le Moniteur, et aussi Archives nationales, $F^{17}$, carton 1228. 
velles richesses à l'établissement (1). En prairial nous royons le Comité saisi d'une autre affaire. Il s'agit de deux palmier's qui existent à Brunoy dans le jardin de Xavier Capet et qu'il importe de garder à la nation: ils ont été vendus, mais on indemnisera l'acheteur. Ces palmiers, destinés dans le principe à l'ornement du jardin des Tuileries, sont, croyons-nous, ceux qu'on voit encore de chaque côté de la porte du grand amphithéâtre au Jardin des plantes. Le bâtiment qu'ils décorent est lui-même une création du temps de la Terreur. Dès le 8 ventôse, en effet, le Comité de salut public avait assigné un premier fonds de 40,000 livres pour l'agrandissement du Muséum, et cette somme avait été tout d'abord affectée à la construction d'un vaste amphithéâtre (2). On se mit à l'œurre arec une activité que nos établissements publics n'ont pas toujours retrouvée sous d'autres gouvernements : dès le mois de floréal nous voyons les premiers mémoires des entrepreneurs arriver à la trésorerie (3).

Mais ce n'était que le prélude. On ne songe à rien de moins qu à tripler l'étendue du jardin, pour se conformer aux prescriptions du décret du 16 germinal. Le Muséum d'histoire naturelle s'étendra d'un côté jusqu'au boulevard de l'Hôpital et au marché aux cheraux, englobant la rivière de Bièrre; et de l'autre côté jusqu'à la rue Saint-Bernard sur tout l'espace occupé par la Halle aux vins. L'architecte Molinos est char vé d'étudier le

(1) Voir la lettre que Daubenton écrit au ministre de l'intérieur Paré, en Jui adressant copie de celle du Comité de salut oublic en date du 19 pluviòse ( $\mathrm{F}^{17}$, carton 1109 ).

(2) On a répété souvent qu'il n'y arait point d'enseignement à cette époque á Paris. La construction du grand amphithéảtre serait une réponse suffisante. Voici un autre détail qui montre combien cette opinion est fausse. Zangiacomi, le conventionnel, communique, le 23 prairial an II, une note a la Commissiou dezarts. Les éléres qui suirent le cours de botanique, dit-il, ouvert au Jardin depuis quelque temps, ont besoin des Démonstrations élèmentaires de botanique de Gilibert, publiées à ComnuneAfranchie chez les frères Bruisset; mais ceux-ci ont été guillotinés, et tout ce qui leur restait de l'édition de ce livre est sous le scellé. Il demande si on ne pourrait, daus l'intérêt des élẻres, le remettre en vente. Les libraires le font payer 70 francs et il en raut 20. La demaude, approurée par la Commission des arts, est renroyée au Comité d'instruction (Fij, carton 1224).

(3) Le premier payement arait élé fait à l'entrepreneur de maçonnerie le 30 germinal ( $F^{17}$, carlou 1222). On arait probablement commencé à la même époque les travaux de la galerie supérieure, car nous royons par une lettre de Jussieu, en date du 22 fructidor, que ces travaux sont suspendus, faute de place pour emmigasiner les objets déposés dans les combles $\left(\mathbf{F}^{17}\right.$, carton 1229$)$. 
plan et les devis, et dès le 3 messidor il remet son travail (1). Il s'agit d'une dépense de 4,166,400 livres, somme énorme pour le temps, énorme au milien des circonstances où se trouvait la France, jugéc nécessaire cependant pour rendre l'ancien Jàdin du roi digne de la nation, qui doil y roir réunies, comme en un temple, toutes les productions vivantes de la nature entière, recueillies par la Victoire. Trois arrêtés successifs du 27 et du 28 floréal et du 3 () prairial (2) pressent la solution de l'affaire : on suspend la vente des biens nationaux provenant de l'ancienne abbaye Saint-Victor et compris dans le périmètre du projet Molinos; on suspend les constructions commencées dans l'enclave du projet, on prépare l'expropriation des maisons particulières, qui perdent tout à coup de leur raleur, sujet de plainte pour les habilants (3). Qui veut, qui fait tout cela? - Le Co-

(1) Voir celui-ci ( $\mathbf{F}^{17}$, carton 1229).

(2) L'arrêté du 27 tloseal est bien connu, quoiqu'un certain nombro d'auteurs qui l'ont cité aient jugé à propos de ne point donner les sjgrnittures qui sont au bas. Larrêté du 30 prairial porte "que la Coumission des travaus publies donnera sur-le-champ les ordres nécessaires pour faire suspendre, jusqu'à nouvel ordre, les constructions des maisons dans l'enclave projetée " $\left(1^{17}\right.$, carton 1229). Larrite du 28 florial porte que les ciloyens employes dans le Muséum d'hisloile naturelle se concerteront sans délai avec la Commission des arts, pour réunir dans un dépôt les divers ohjets relatifs il l'histoire naturelle, et qui peurent servir a l'organisation et á l'emichissement de ce monument national. Ils ćtablirout les moyens de conservalion quils jugeront convenables. $\left[\mathbf{F}^{17}\right.$, carton 1284.)

Le 27 floréal, le Comité de salut public prenait un autre arrêté portant qu'il sera établi un enseignement public des larigues étrangéres de lous pays autres que ceux avee lesqucls la République est en gruerre, it l'usage des marius, des naturalistes, des agents de la liejpublique á l'extérjeur et des citoyens qui culliveut les sciences. Il y aura une imprinerie dans laquelle seront réunis tous les caracteres lypographiques etrangers que posséde la République. La Commission d'iustruction est chargée le rechercher le personuel enseignant, et le Comiti: des domaines le local nécessaire. (Voir Décade philosophique.) L'Ecole des langues orientales, dont on roit ici le germe, ne fut instituce que le 10 germinal an IJ. Le 2.s floréal, le Comile de salut public, sans doute daus la mème vue, avait rendu un arrété relatif' ì l'achat de caractìres d'iupriuerie allemands. Foussedoire, représentant en mission daus les départements des losges et du Ilaut-Rhin, icrit au Comiti quil a eru devoir surveiller lui-mêue l'exécution de cet arrèté, el qu’il est lui-mċme allé acheter ces caractères d'imprimerie i bile, chez Ilaas.

(3) 25 messidor. Baudoin, dont la maison est en soulfinnce, par suite de l'arrêté suspensif pour le Mluséum, est invile à s'udresser au représentant Fourcroy et aux citoyeus chargés ite surveiller la coustruetion du Muscum. (Registre de la Cummission des arts.) De même, un échange d'immeulles avec le citoyen Leger est renvoyi par le Comite de salut fublic au Comite des domaines ( $\mathbf{F}^{17}$, carten 1229$)$. 
mité d’instruction publique? nullement. Les arrètés du פi floréal et du 30 prairial sont signés Billaud-Tarenne, Barère, Carnot, Prieur, Robespierre, Collot d'Herbois, Couthon, Lindet (1).

\section{VII}

Quels honmes est-ce donc que ces membres du Comité de salut public, qui prennent ainsi violemment une place inattendue dans l'histoire des sciences? Ces hommes ont l'Europe à vaincre, la Vendée à étouffer, la France à organiser, et ils trouvent eneore le temps de faire pour les sciences et les arts toutes ces choses; encore n'arons-nous pas tout dit. Et quelle part inégale, après cette œurre de Titans accomplie en commun, l'histoire leur réserre! Quel supplice que celui de Robespierre, et que d'imprécations sur ce nom! Qui parle de Lindet et de Prieur? Qui ne connaît Carnot? La gloire, l'oubli, Cayenne, l'échafaud se partageront les douze membres du Comité de salut public de l'an II.

Hérault de Séchelles s'élait spontanément éloigné presque dès le début; Prieur (de la Marne) fut tout le temps en mission; Jeanbon Saint-André, chargé dorganiser la flotte, parait à peine; les véritables détenteurs de la puissance presque souveraine du Comité de salut public furent Billaud-I arenne, Barère, Collot d'Herbois, Carnot, C.-A. Prieur (de la Còte-d'Or), Lindet, Robespierre, Couthon et Saint-Just, et encore ce dernier n'estil là que dans les moments déeisifs, passant l'autre moitié de son temps aux armées du Rhin et du Nord.

Il est facile de partager ces hommes en groupes distincts. Leurs contemporains, dit-on, l'avaient déjà fait. Sans examiner le mérite de ces sortes de classifications qui divisent après coup les responsabilités et permettent à chaque parti de faire son tri, il est certain qu'on n'est pas actuellement en état d'établir, par' des preures directes, la part qui revient dans les créations seientifiques de l'an II à chacun de ces hommes, si différents d'humeurs et de tempérament sinon de convictions. Tout au

(1) Ce projet, poursuivi jusqu'en rentose an III, fut abandonné à partir de cette époque, après aroir surcessirement passé par le Comitẻ des traraux publics et par le Comité d'instruction ( $\mathbf{F}^{17}$, carton 1229). Le 21 rendémiaire an III, le Comité d'instruction invitait assez impérativement le Comitédes travaux publics à lui faire passer le rapport (Ibid.) : sigué Thibaudeau, Villar, Massieu, Arbogast. Le ̈̈ rendẻmiaire, les soumissions étaient arrivées à la Comuission des travaux (Ibid.). 
plus voyons-nous C.-A. Prieur s'occuper presque seul des aérostats et de l'établissement de Meudon, comme Carnot s'était réservé la conduite des opérations militaircs.

Que les arts de la guerrc aient trouvé dans les officicrs du génie, comme l'étaient C.-A. Prieur et Carnot, d'intelligents promoteurs au sein du Comité de salut public, cela semble tout naturel, et voilà la création de l'Ecole polytechnique et de l'Ecole de Mars, l'agrandisscment de l'Ecole des mines expliqués. Mais n'étaient-ils pas étrangers pour le moins autant que leurs collègues aux sciences naturelles? Qui donc parmi les membres du Comité s intéressait aux richesses scientifiques des Pays-Bas, aux tableaux, aux arbres rares du Muséum, à l'enseignement de la musique?

Pas un mot dans la bouche de Robespierre, pas une ligne dans les papiers de cet intarissable discoureur ne témoignent d'un intérèt quelconque pour les sciences, les lettres, les arts, pour toutes ces mesures qu'il contresigne. Tout au plus pourrait-on supposer que le disciple passionné de Rousseau eût pris quelque part aux arrêtés sur le Muséum, sur les jardins, si les soins politiques ne l'avaient entièrement absorbé. Saint-Just n'est qu'un Lacédémonien égaré au temps de l'Encyclopédie, il méprise ce qu'aime Athènes. Couthon était beaucoup plus de son temps. On lui a fait un mérite d'avoir apporté quelque tempérament au décret de la Convention qui ordonnait de détruire les quartiers riehes de Lyon. Il est douteux que la pensée soit venue à Couthon de se mettre au-dessus des décrets de la Convention; il est probable qu'il fit ce qu'il put. Lui-mème parle $\dot{a}$ ce moment, dans ses lettres, du désir qu'il a d’aller réduire en cendres Toulon révolté, et, en post-scriptum, il s'enquiert soigneusement s'il peut conserver un télescope " de l'infàme Précy ), le chef des insurgés lyonnais, et qu'il désire garder comme pièce d'histoire (1). L'histoire de ces temps troublés est toute dans ce petit fait. Il y a dans chaque révolutionnaire de l'an II deux hommes: l'un, fils aimable de ce xiri ${ }^{\mathrm{C}}$ siècle si curieux des choses de sciences; l'autre fils de ses œurres, épris d'un formidable labcur, prêt à étouffer dans les ruines et à noyer dans le sang tout ce qui signifie à ses yeux contre-rérolution.

Après Couthon, Collot d'Herbois vient ¿ Lyon organiser la

(1) "Mande-moi si le Comité pense que je puisse sans aucun incourénient retenir cette piece." (Lettre de Couthon à Saint-Just, dans les Papiers inédits trouvés chez Robespierre.) 
démolition et la fusillade; Barère veut qu'on efface de l'histoire jusqu'au nom de la cité rebelle; au sein du Comité, e'étaient, avee Billaud-Varenne, ceux qu'on appelait, dit-on, les gens révolutionnaires, ceux qui représentaient le mieux, avec des facultés fort inégales, l'esprit de la Montagne détaché de l'esprit jacobin (1). Les deux premiers ne furent que des hommes médiocres. Barère de Vieuzac, qui signe Barère tout court, tient par sa mère à cette noblesse éclairée du xvur siècle qui avait été le plus ferme appui des encyclopédistes, et de Rousseau lui-même, et qui conduisit en quelque sorte au début la Rérolution par la main. On reste confondu des prodigieuses facultés de Barère (2), à qui rien ne semble étranger. Le manuserit de la Nounelle Héloïse l'oceupe autant que la fabrique d'armes de Meudon. La même main qui amende le décret sur la liberté des cultes rédige le projet de réquisition des cordonniers. Traités, marine, poudres, transports, tableaux du maximum, tout est bon à l'activité de cet homme, dont le rỏle considérable (3) va rester effacé dans le rayonuement, puis dans l'opprobre du nom de Robespierre. N'oublions pas que Barère voulait non seulement l'instruction primaire pour tous les enfants, mais qu'il voulait extirper du sol de France tous les patois, en sorte que jusqu'en Bretagne et jusqu'au fond de l'Alsace on ne parlât plus que la langue nationale : des instituteurs devront être, à cet effet, entretenus par l'Etat dans tous les villages des départements où l'on ne parle pas français. Mesure salutaire, qui eùt peut-être adouci les désastres de notre temps en y laissant l'espérance (4).

(1) [1l n'est pas exact de dire que Collot, Barère et Billaud représentaient l'esprit de la Mlontagne "détaché de l'esprit jacobin ". Tous les trois comptèrent, arant et après le 9 thermidor, au nombre des nembres les plus intluents de la Société des Jacobins. On sait quel rôle important Collot y joua en ventôse an II, lors des négociations avec le club des Cordeliers. Billaud y fut écouté à l'égal de Robespierre, jusqu'à la veille de thermidor. Barère présida les Jacobins en messidor. - J. G.]

(2) .1. Hippolyte Carnot, dans son introduction aux Mémoires de Barère, rappurte un mot de Robespierre, quiil tenait du $\mathrm{D}^{\mathrm{r}}$ Souberbielle, ancien juré du tribunal révolutionnaire : "Dès qu'un travail se prézente, Barère est disposé à s'en charger. Il sait tout, il connait tout, il est propre à tout. " (Mémoires de Barère, introduction, p. S0). Cette opinion de Robespierre est vraisemblable; un homme universel comme Barère devait profondément étonner un esprit aussi réservé que celui de l'orateur des Jacobins.

(3) Dans les tables du Moniteur aucun nom, pas mème celui de Robespierre, ne tient une place égale à celui de Barère.

('́) Rapport sur les idiômes, 8 pluviôse an II. A la vérité Barẻre, dans ses Mémoires, n'est plus qu'un homme assez médiocre; il a perdu ce 
Barere eut sans doute, avec Collot d'Herbois et BillaudVarenne, la plus grande part dans toutes les mesures réparatrices prises par le Connité pour favoriser les choses de seience. Quant ils seront attaqués comme complices de Robespierre, Carnot les défendra. Eux-nèmes se feront gloire, dans leur seconde réponse à Lecointre, d'aroir grroupé autour du Comilé de salut public lourcroy, Guyton, Berthollet, Vandermonde, qu'ils nomment fièrement. "Nous avions besoin d'acier, disentils. Nous l'avions demandé a la fabrication; ce sont les sarants qui nous en dounèrent (1). »

Ce qu'on ne peut nier, c'est que la journée du 9 thermidor laissa inacherée l'ceurre du Comité de salut public. Arec ces hommes indomptables, quoi qu'on pense d'eux, s'en est allé ce grand souffe qui semblait entrainer la liance au pas de charge vers une rénoration scientifique.

Nous royons bien l'annẻe suivante quelques créations nouvelles, les Ecoles centrales, l'Ecole normale (2), l'institut, nous aurons les commissions seientifiques aux armées. Qu'est-ce que tout cela auprès du prodigieux tableau de l'an II? Franchissons deux années seulement : quelle différence! Comme le génie de la France et de ceux qui la gouvernent n'est plus le mème! Victorieuse, puissante, respectée, elle ne trouve plus pour les sciences les mêmes ressources qu'aux jours de la lutte; les établissements scieutifiques languissent, en attendant la décadence

souflle de 93 'jue Napoléon, au fort de l'invasion, vonlait rappeler au cocur le ses géméraux : "Allons, Augrerean, il n’est plus question d'agir comme dans les derniel's temps, mais il fiut reprendre ses buttes et sa résolution de 93! " Lettre à Angereau, 21 férrier 18t:́)

(1) Il est curieux de roir ce ròle du Comité de salut public attesté par 1]. lourcy : "Il y avait alors, auprés du Comite de salut public, une espéce de congrés de sarants (c'est de la Commission des arls que parle M. Fourcy, en se méprenant à la fois sur sun rôle et sur sa situation, où la plupart des sciences exactes et naturelles se trouvaient digmement représentées. C'est le lá que partirent a la voix du Comité souverain ces instruetions lumineuses, ces inventions sondaines, ces expédients ingénieux et rapides qui, dégrgeant les procédés des arts des vieilles olniéres de la routine, élevaient tout i conp leurs produits an nireau des iumenses besoins de la Rérolution" (Hisloive de l'Ecole polytechnique, p. 13). - [Nous ne croyous pas, comme nous l'arous dejà expliqué plus laut, que M. F'ourey ait voulu parler de la Commission des arts : ce qüil appelle " une espéce de Congrés de savants ", c'est précisiment cetle réunion de sarants "groupés autour du Comité de salut public ", et où figmaient Guyton, loureroy, IIassenfratz, Vandermonde, Berthollet, Leblanc, etc., etc. - J. G.j

(2) [L'Ecole normale ne fut instituée que par le décret un 9 brumaire an 111 , wais le Comité d'instruction publique en avail élaboré le plan avant thermidor, en floréal et prairial. - J.G.] 
durement payẻe de nos jours par la défaite. En l'an $\mathbb{N}$, il s'agrit d'une somme de 1.236 francs en numéraire dont le Muséum i besoin pour acheter des vitres. Le IIuséum éprouve un premier refus enveloppé dans une phraséologie arministrative toute nouvelle. Ce n'est plus ce style étrange de l'an II, étrange tout ¿a la fois par sa brièreté et son emphase et qui semble d'un autre monde! Ici nous abordons aux terres connues, les hommes yui entrent maintenant en scène sont retombés à notre taille; ils parlent et ils agissent comme on parle et comme on agrit encore trois quarts de siècle après eux. "J'aurais désiré, mon wher collègue, écrit un ministre à l'autre (1), pouroir accorder is un établissement aussi intéressant tout ce qui peut aider a ses besoins, mais ceux de la guerre sont tellement urgents, etc. " On finit cependant par décider la dépense luit jours après, le Directoire l'ayant approurée. L'année suivante le Iruséum, plalement, par son directeur Jussieu, va au-derant des refus : "Les professeurs n'ignorent pas combien les circonstances sont difficiles; aussi ne rous retracent-ils pas tous les besoins de l'établissement. Si vous estimez dans rotre sagesse qu'on puisse quelque chose, ete. $(\boldsymbol{2})$. "C'était l'autre ton que parlaient les sirants du Muséum, pendant la Terreur, à ces autres hommes qui étaient alors au pouvoir et qui n'accablaient les professeurs que de richesses et d'agrandissements.

Surtout quon ne dise pas que l'arrent manquait; les besoins uu Trésor étaient au moins aussi grauds, on en conviendra, yuand la France était, comme a dit plus tard Lindet, "un camp qu’il fallait nourrir ». Non. Mais l'esprit scientifique s'en était illé, on ne tenait plus en mème estime les mêmes choses. X'avons-nous pas de cela une expérience toute récente? Après des désastres inouïs, arec tout à réparer au dedans, et tout à payer au dehors, n'arons-nous pas ru nos établissements scientifiques un peu plus riçhes, un peu mieux dotés après la guerre de 1870, alors qu'arant elle l'argent manquait, disait-on, pour les choses de l'enseignement?

Il est impossible de n'en point convenir. L'an II marque bien réellement une date importante dans l'histoire des sciences françaises. Non seulement elles sont représentées par une pléiade d'hommes illustres; non seulement elles roient

(1) Archires nationales, $\mathrm{F}^{17}$, carton 1109 : Lettre du ministre des finances au ministre de lintérieur, $T$ prairial an IV.

(2) Archires nationales, Ibid. : Lettre de Jussieu aux directeurs, $S$ rendémiaire an $\mathrm{V}$. 
grandir et naitre une foule d'établissements d'enseıgnement; mais elles ont sauvé le pays, elles sont plus près du gouvernement qu'en aucun temps. Les services qu'elles ont rendus arant le 9 thermidor font jeter les yeux, pour succéder à Robespierre, à Couthon et à Saint-Just, sur deux savants, deux chimistes, Guyton et Fourcroy.

Puis la Convention termine cette année d'un labeur sans exemple par le décret suivant, qui montre qu'elle se croyait seulement au début de sa tûche: "La Convention nationale charge tous ses comités et tous ses membres de méditer sur les moyens à prendre pour vivifier l'agriculture, l'industrie, les arts, les sciences et le commerce, et de lui présenter leurs vues sur cet objet important qu'elle recommande à la discussion de toutes les sociétés populaires; elle invite tous les citoyens de s'en occuper et de lui faire parvenir le résultat de leurs méditations 》 ( 28 fructidor).

Quant au Comité de salut public décapité le 9 thermidor, ses actes, mieux que tout, montrent la part qui lui revient dans le mourement, les réformes et les créations scientifiques de l'an II. Ou bien il faut lui contester l'omnipotence dont on lui fait un crime; ou bien, au milieu de tant de reproches (1), il fant lui rendre cette tardive justice que plus qu'aucun gouvernement au monde il a honoré les sciences et compris leur rôle social.

(1) Dans le courant de l'année, la Convention avait voulu faire dresser l'inventaire de toutes les richezses naturelles de la France, véritable description scientifique de la patrie. Elle s’ètait adressẻe à Daubenton. Nous lisons, dans une lettre de la Commission exécutive de l'instruction publique à Diubenton, en date du 25 prairial : " Le projet de questions que tu as apporté toi-même à la Commission remplit ses vues. Elles forment la base de la circulaire qu'elle doit adresser au corns administratif. Elle espère en recueillir des renseignements utiles à la connaissance de nos productions naturelles, au commerce et aux arts. Tu aurais pu indiquer dans quels départements existent ces productions... La Commission répandra les instructions de Daubenton, don le bienfait ne s'est pas étendu aux campagnes." (Archives nationales, F17, carton 1228.) 


\section{Exlrail des Slaluı}

approuvés par l'assemblée du 15 mar's 1888.

L'objel de la Société de l'Histoire de la Rérolution est:

De faire prévaloir la méthode scientifique dans les études sur la Révolulion française;

D'offrir un point de ralliement aux personnes qui, à Pariz et dans les départements, soccupent de l'Histoire de France depuis 1789 ;

De publier des lexles inédits on rares el des œuvres originales louchanl l'histoire de France depuis 1789;

D'organiser des conférences historiques à Paris el dans les départements. .

La Suciélé se compose de membres fondateurs el de membres adhérents. Les membres fondateurs sont les personnes qui ont versé, une fois pour toutes, une somme d'au moins วo00 francs. Les membres adliérents versent une colisation annuelle de 20 francs. Les uns el les autres reçoirent gratuitement toutes les publications de la Société.

Les personnes qui désirent entrer dans la Société doivent se faire présenter par deux membres du Comité directeur, qui statue sur l'admission.

\section{PUBLIGATIONS}

DE LA

\section{SOCIETTE DE L'HISTOIRE DE LA REVYOLU'TION FRANCQASE}

En vente au siège de la Sociélé, 3, rue de Fursténberg.

Qu'est-ce que le Fiers élal? par EMnanuer. SiEYès, précédé do l'Essui sur les privilèges, edilion critique arec une introduction pal Edme Champlos. 1888, in-S......... $4 \mathrm{fr}$.

Lisle des Membres de ln Noblesse impériale, d'après les registres de lethes patentes, par Emar. Campardox. 1889 , in-8.................. . . . $3 \mathrm{fr}$.

Les Conventionnels, listes pal départements et par ordie alphaliétique, par Jules GulfFrer. 1889, in-8. . . . . . 5 fr.

Jémoires secrets re foumier l'Américain, publiés par F.A. Au-

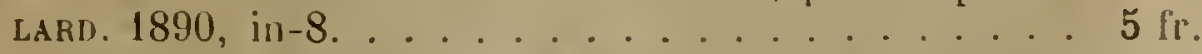

La Joumée du 14 Juillet 1789 , par PITra, avec notes el inlruduction par Jules Flammermoxt. 1892, in-8. . . . . $6 \mathrm{fr}$.

Mémoires de Clenumelte sur la vévolution du 10 cioûl 1792, publiès par F.-A. Aulard. 1893, in-8.......... $3 \mathrm{fr}$.

Les Régicides, par E. Becfoume. 1893, in-8....... . $3 \mathrm{fr}$

Voir au verso la suite de cette liste des publications de la Société. 


\section{DERNIÈRES PUBLICATIONS}

DR IAA

SOCILTY DE LHISTOIRE DE- LA REYOLLTION FRANCAISE

En vente au siègr de la Société, 3, rue de Furstenberg

- (Voir au recto la liste des précédentes publications.)

Les gincrunx mor's pour la patrie (179.2-1804), nolices biugraphiques, par Jacques Ciaravar, publiées par son père. 1893, in-8................ $5 \mathrm{fr}$.

Le Serment du Jeu de Paume, fac-similé du lexte el des signatures, avec une introduclion el des notes par $\Lambda$. BRETris, et un avant-propos par EDME Champios. 1893 , in-8. . . $10 \mathrm{lr}$.

Legistre des Délibéralions du Consulal rrovisoire, pullie par 1.-A. Aulakd. 1894, in-8 ......... $3 \mathrm{fr}$.

Procés-verbaux de la Commune de Paris (10 aoûl 1792fer juin 1793), publiés par Maurice Tourneux. 1894, in-8. $5 \mathrm{fr}$.

Les Grades mililaires pendant la Révolution, par ÉTIExis CuaRAVAY. 18950, in-8. (Non mis en vente.)

Récil des séances des députés des Communes, depuis le 5 mai 1 \% $\$ 9$ jusquau 12 juin suivant, réimpression, avec un avertissement par F.-A. AUlard. 1893, in-8. . . . . . . 4 fr.

Les prix désignés ci-dessus sont ceux du tirage sul papier ordinaire, seul mis dans le commerce.

Première tuble gènérale analy tique el alphabétique de la Révolution trancaise (1881-1890). Paris, 1890, in-8.... 1 fr. 50

Seconde table générale analylique el alphabétique de la liévolution francaise (1891-1893̈). Paris, 1895̆, in-S..... $1 \mathrm{fr}$. วั0 SOUS PRESSE :

Lisle des Constifuants, par A. Brette.

PRII DE LABONAEMENT A LA REYOLULION FRANCAISE paris et départements. . . . . . 20 trancs. Etranger. ........... . . 2. francs.

Les membres de la Société de l'histoire de la Révolution recoivent gratuitement la lievue el les publications de la Société.

Il est fail de ces dernières un lirage sur papier de Hollande, exclusivement destiné aux sociétaives el non mis dans le commerce.

Paris. - Imprimerie I. Msneturx, 1, rue Cassette. 





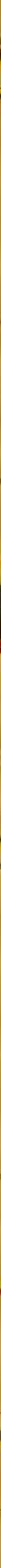




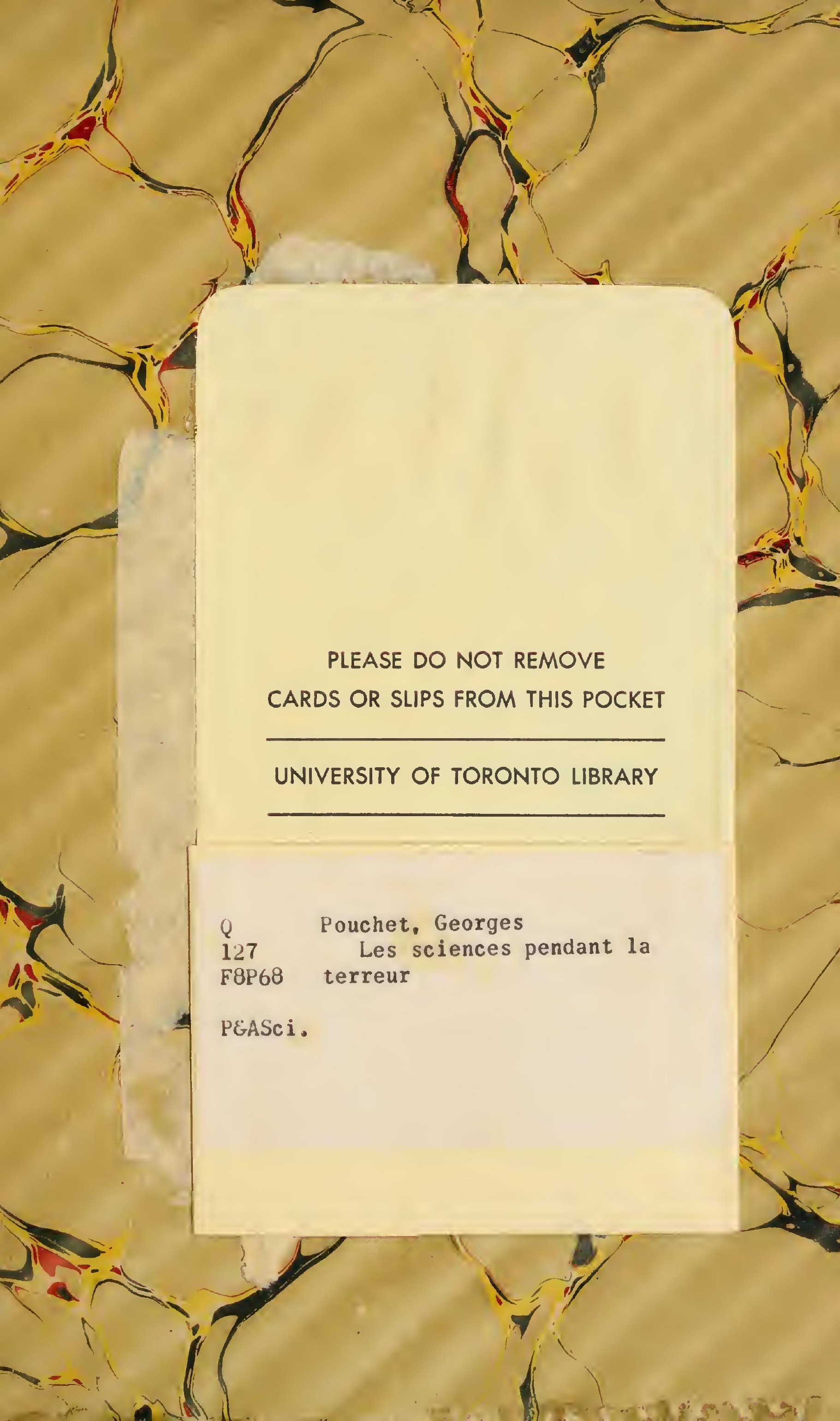


